\title{
Research Paper \\ Investigation the structural model of the relationship between cognitive emotion regulation and defensive lifestyles with quality of life mediated by Alexithymia in patients with hypertension
}

\author{
Ali Tahamtan', Maryam Kalhornia Golkar², Kobra Haj Alizadeh ${ }^{3}$ \\ 1. Department of Psychology, Kish International Branch, Islamic Azad University, Kish Island, Iran. \\ 2. Associate Professor, Department of Psychology, Karaj Branch, Islamic Azad University, Karaj, Iran. \\ 3. Associate Professor, Department of Psychology, Bandar Abbas Branch, Islamic Azad University, Bandar Abbas, Iran.
}

Citation: Tahamtan A, Kalhornia Golkar M, Haj Alizadeh K, Khodabakhshi Koolaee A. Investigation the structural model of the relationship between cognitive emotion regulation and defensive lifestyles with quality of life mediated by Alexithymia in patients with hypertension. J of Psychological Science. 2022; 20(108): 2285-2305.

URL: https://psychologicalscience.ir/article-1-1122-fa.html
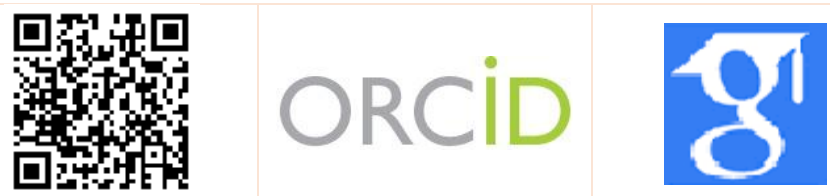

$\underline{10.52547 / J P S .20 .108 .2285}$

\section{A R T I C L E I N F O A B S T R A C T}

Keywords:

Quality of life,

Emotional Cognitive

Regulation,

Alexithymia,

Defensive styles,

Blood pressure

Received: 23 Jan 2021

Accepted: 27 Feb 2021

Available: 20 Feb 2022
Background: High blood pressure is one of the most common and important factors threatening individuals' mental health and quality of life. Accordingly, the study of important psychological factors such as cognitive regulation of emotion and defense styles used by patients with high blood pressure, and the impact of these variables on their quality of life can help them improve their psychological state.

Aims: The purpose of this study was to investigate the structural model of the relationship between cognitive emotion regulation and defensive lifestyles with quality of life mediated by Alexithymia in patients with hypertension.

Methods: The present study is descriptive and of correlations and structural equations type. The statistical population includes 700 patients with hypertension who referred to Shiraz Heart Hospital in the spring and summer of 1398. 480 patients were selected from among them. The research instruments included the Cognitive Emotion Regulation Questionnaire of Garnefski et al. (2007), the Defense Styles Questionnaire of et al. (1993), Quality of Life Questionnaire of the World Health Organization (1996) and the Toronto Alexithymia Scale-20 Questionnaire by Tyler et al. (1994). Data were analyzed by Kolmogorov-Smirnov test, linear regression and structural equation modeling using SPSS 25 and LISREL 8/8 software.

Results: The relationship between emotional cognitive regulation variables and defense styles with quality of life variable mediated by alexithymia in patients with hypertension is significant $(\mathrm{P}<0.001)$.

Conclusion: Applying cognitive emotion regulation strategies and defensive styles to overcome alexithymia by patients with high blood pressure can affect the quality of life of these patients.

* Corresponding Author: Maryam Kalhornia Golkar, Associate Professor, Department of Psychology, Karaj Branch, Islamic Azad University, Karaj, Iran.

E-mail: maryamgol1986@yahoo.com

Tel: (+98) 9126082921

2476-5740/ (C) 2021 The Authors. This is an open access article under the CC BY-NC-ND license

(https://creativecommons.org/licenses/by-nc/4.0/). 


\section{Extended Abstract}

\section{Introduction}

Nowadays, due to lifestyle changes and increased stress and anxiety, cardiovascular disease has increased significantly in different communities (Tavakoli et al. 2020). Studies in different countries have shown that hypertension is one of the important factors that play a key role in the spread of cardiovascular disease (WHO). Many studies have found that psychological stressors such as anxiety and stress, anger, lack of emotion control, depression caused by poor quality of life, and negative emotions lead into hypertension more than other environmental factors (Ifeagwazi, Egberi \& Chukwuorji, 2018). Studies have indicated that emotional disorder and stressful events have a significant relationship with physiological indicators such as hypertension, so the use of emotion regulation strategies can affect the relationship between emotion and hypertension. One of the strategies for emotion regulation is the use of cognitive emotion processes, in which the person can control emotion stimuli (McRae, 2016). Inability to regulate emotions is associated with physical and mental problems in people with alexithymia. Among the psychological dimensions associated with hypertension, alexithymia has been studied as a personality problem in individuals. Studies have revealed that alexithymia can help a person temporarily and of course abnormally relieve themselves of the stresses of painful emotions by avoiding painful factors based on physiological stimuli (Blakey et al. 2017). As a result, it predisposes the person to diseases such as high blood sugar, hypertension, irritable bowel syndrome (Porcelli, Carne \& Leandro, 2017) and tension headaches (Esin, Gorobets, Khairullin \& Esin, 2017) and so on.

In other studies, alexithymia has been introduced as a defense or coping mechanism that a person uses to protect himself or herself against emotional helplessness that occurs in traumatic situations (Besharat and Khajavi, 2013). The defense mechanisms are responsible for protecting the "I" in the face of different forms of anxiety. They are divided into three types, including immature, neurotic and mature. Immature and neurotic defenses are maladaptive and inefficient coping styles. Mature defenses are considered as adaptive, normal and efficient coping methods (Talepasand \& Mahfar, 2018). Emotion-based defense mechanisms are negatively associated with systolic and diastolic blood pressure, and suppression and denial mechanisms are positively associated with systolic and diastolic blood pressure (Ali Akbari Dehkordi, Salehi \& Rezaei 2013). Studies have also shown that the quality of life component plays a major role in predicting the degree of defense mechanism and its high level indicates the health of the person (Gharibi, Rostami, Mohammadian Sharif \& Manqi, 2016). Hypertension affects a person's quality of life by reducing a person's physical abilities and physiological capacities (Nemat \& Tavousi, 2017). Also, the use of adaptive cognitive emotion regulation strategies to cope with stress has a positive effect on quality of life. Every person who can cope with his or her deep problems and not lose his or her power against inevitable inner conflicts, he or she will have a mental health and a good quality of life (Saeidian, Sohrabi and Zemestani, 2019).

Quality of life is one of the most important components of the general concept of health, so that their quality of life should be examined to determine the people health needs and promote their health. Also, hypertension is one of the most common and important threats to mental health and quality of life and almost a quarter of all deaths in the elderly are due to hypertension or its complications (Saeidian, Sohrabi and Zemestani, 2019). Thus, to reduce blood pressure and improve the quality of life of these patients, it is necessary to address the variables that can be related to the quality of life of these patients. In the present study, psychological variables were studied in the form of a research model to determine the direct and indirect relationships between the variables of emotion recognition regulation and defense styles and quality of life mediated by alexithymia in people with hypertension to improve the psychological conditions of patients with hypertension.

\section{Method}

The present study is descriptive-correlational research conducted using structural equations 


\section{Monthly Journal of Psychological Science}

Vol. 20, No. 108, Winter(March) 2022 method. The statistical population of the present study consisted of 700 patients with hypertension referred to Shiraz Heart Hospital in the spring and summer of 2019. Among them, 480 people were selected by using a convenience sampling method. Inclusion criteria were having an age between 35 and 50 years, minimum systolic and diastolic blood pressure of 9-14, having at least one year of hypertension and having reading and writing skills. Exclusion criteria were having any other medical illness as well as the presence of a major psychiatric disorder mentioned in the patient's medical record and the use of psychiatric medications. In this study, ethical considerations were considered and the people who participated in this study were assured that their information would remain confidential and would not be provided to anyone without their permission. Then, the collected data were analyzed using Smartpls, LISREL 8.8, and SPSS25 software.

Cognitive Emotion Regulation Questionnaire (CERQ): This questionnaire was developed by Garnefski and Kraaij in 2007 and has 36 items.

Its questions are scored on a five-point Likert scale. This questionnaire includes 9 subscales with two positive and negative strategies. Scores range from 36 to 180 . Garnefski stated the reliability positive and negative strategies and whole questionnaire at 0.91 , 0.87 and 0.93 , respectively, using Cronbach's alpha coefficient. Pazuki, Kuchak Entezar \& Ghanbari Panah (2015) evaluated the reliability of this questionnaire in Iran and reported the Cronbach's alpha coefficient at 0.63 for blaming others, 0.61 for self-blame, 0.54 for rumination, 0.60 for catastrophizing, and 0.57 for acceptance and Cronbach's alpha coefficient for the whole questionnaire was obtained at 0.81 .

Defense Styles Questionnaire (DSQ): This questionnaire was designed by Andrews, Singh and Bond in 1993. It includes 40 questions, scored on a Likert scale from 1 (strongly disagree) and 9 (strongly agree). This questionnaire measures 20 defense styles based on three subscales of mature, neurotic and immature defense styles. The score for each defense style is a number between 2 and 18. Besharat (2012) evaluated this questionnaire in his research and reported the Cronbach's alpha coefficient from 0.83 to 0.94 for the mature style, from 0.81 to 0.92 for the immature style, and from 0.79 to 0.91 for the neurotic style.

World Health Organization Quality of Life Questionnaire (WHOQOL-BREF): In 1996, a group of WHO researchers designed a quality of life questionnaire based on a 100-question version. This questionnaire includes 4 subscales of physical health, mental health, social relations, environmental health and a general score. Scores range from 0 to 100. In their research, Rafiei et al's (2014) reported that Cronbach's alpha coefficient of the whole questionnaire at 0.93 and the reliability standard coefficients were reported between 0.74 and 0.90 . Spearman correlation coefficient and agreement coefficient of the whole questionnaire were 0.89 and 0.88 , respectively.

The Toronto Alexithymia Scale-20 (TAS-20): This questionnaire was designed by Bagby, Tyler and Parker in 1994. The questionnaire includes 20 questions in which three subscales of difficulty in identifying emotions, difficulty in describing emotions and objective thinking are measured in a five-point Likert scale ranging from strongly disagree $=1$ to strongly agree $=5$. The score range for the whole scale is between 20 and 100. In his study, Taylor obtained Cronbach's alpha coefficients at 0.74 for total Alexithymia. Internal consistency coefficients for three scales of difficulty in recognizing emotions difficulty in describing emotions, and objective thinking was also reported at $0.73,0.75$, and 0.72 , respectively, indicating satisfactory reliability.

\section{Results}

Investigating the descriptive demographic statistics of this study showed that among the 480 subjects, 248 were male and 232 were female. Also, 100 of them were between 35 and 40 years old, 222 were between 41 and 45 years old and 158 were between 46 and 50 years old. In this study, 88 people had only reading and writing skill, 81 people had secondary level of education, 146 people had diplomas, 107 people had associate degree, 48 people had bachelor degree and 10 people had master degree and higher. Moreover, 96 people had a history of hypertension for between 1 and 5 years, 249 people had a history of 


\section{Monthly Journal of Psychological Science}

hypertension for between 6 and 10 years, and 135 people had a history of hypertension for between 11 and 15 years. The mean of all studied variables, regardless of the standard deviation, was almost at average level. To use these variables in modelling, one-variable normality test (Kolmogorov-Smirnov test) was used. The probability value for all variables was greater than 0.05 . All variables had a normal distribution so the assumption of normality was not rejected for any of the variables. Pearson correlation coefficient was performed to investigate the examine lack of multicollinearity between variables, relationship intensity and relationship type (direct and inverse). The correlation coefficient between all variables was positive and significant, indicating a direct relationship between the variables $(\mathrm{P}<0.001)$. The highest correlation coefficient was observed between 2 variables of defense style and quality of life (0.643) and the lowest correlation coefficient was found in the relationship between the 2 variables of cognitive emotion regulation and alexithymia (0.112).

VAF statistic was used to determine the intensity of the effect of the mediating variable. According to the results, the relationship between the defense styles and quality of life mediated by alexithymia was 0.52 , meaning that about $52 \%$ of the relationship between defense style and quality of life was explained by mediating variable of alexithymia. Also, the relationship between cognitive emotion regulation and quality of life mediated by alexithymia was 0.49 , meaning that about $49 \%$ of the relationship between cognitive emotion regulation and quality of life was explained by mediating variable of alexithymia. The value Durbin-Watson statistic was 1.7999 , so it was in the standard range of 1.5 to 2.5 , indicating the independence of the residuals. Then, the structural model (SEM) was analyzed (Figure 1). First, fit indices of X2, NNFI, NFI, GFI and CFI were calculated. The ratio of X2/df was less than 3 and the value of RMSEA was close to zero. The values of the other fit indices were close to one. Thus, the model had a good fit $(\mathrm{P}<0.001)$.

According to the results of Table 1, the standard coefficient between the components of immature and neurotic defense style and quality of life variable was obtained between -0.3 and -0.6 , indicating a negative, moderate and significant relationship between these variables. Accordingly, a positive, strong and significant relationship was observed between negative cognitive emotion regulation, and alexithymia and a negative, strong and significant relationship between cognitive regulation of positive emotion and alexithymia. The relationship between the components of mature and neurotic defense style and alexithymia was positive, moderate and significant, and the relationship between immature defense style and negative alexithymia was negative, moderate and significant. Also, a negative, moderate and significant relationship was observed between negative cognitive emotion regulation and quality of life and a positive, strong and significant relationship was observed between positive cognitive emotion regulation and quality of life. There was also a negative, strong, and significant relationship between alexithymia and quality of life. Based on the results, it was concluded that the relationship between cognitive emotion regulation and defense styles and the quality of life with a mediating role of alexithymia in patients with hypertension was significant ( $\mathrm{P}$ $<0.001)$.

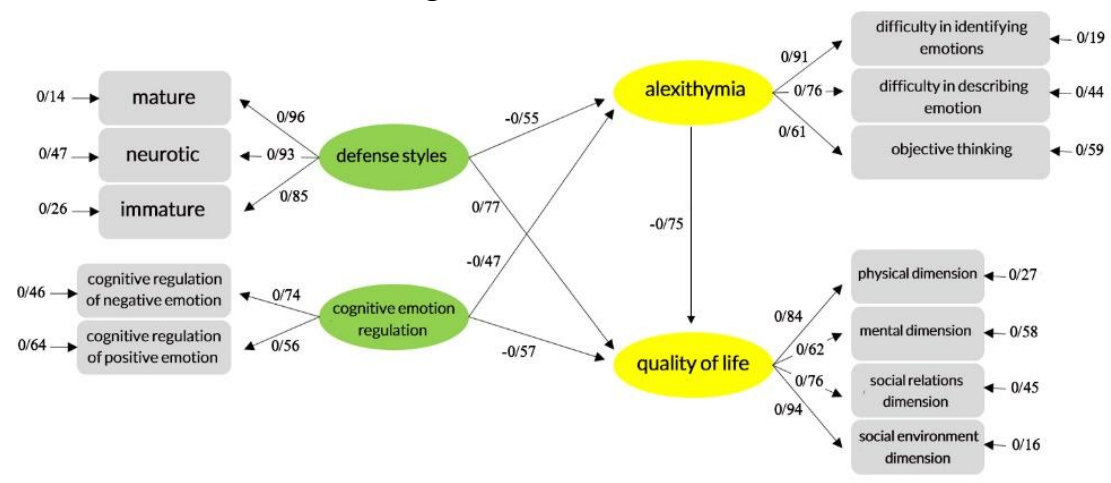

Figure 1. Fit structural model to explain the structural relationship of variables 
Table 1. Direct and indirect standard path coefficients between research variables

\begin{tabular}{|c|c|c|c|c|}
\hline Variable & $\begin{array}{c}\text { direct standard } \\
\text { path coefficients }\end{array}$ & $\begin{array}{l}\text { indirect standard } \\
\text { path coefficients }\end{array}$ & $\begin{array}{c}\text { Standard } \\
\text { error }\end{array}$ & $\begin{array}{c}\text { Probability } \\
\text { level }\end{array}$ \\
\hline Cognitive emotion regulation - quality of life & $-0 / 57$ & - & $0 / 042$ & $<0 / 001$ \\
\hline Cognitive regulation of negative emotion - quality of life & $-0 / 47$ & - & $0 / 156$ & $<0 / 001$ \\
\hline Cognitive regulation of positive emotion - quality of life & $0 / 76$ & - & $0 / 122$ & $<0 / 001$ \\
\hline Defense styles - quality of life & $0 / 77$ & - & $0 / 014$ & $<0 / 001$ \\
\hline Developed - quality of life & $0 / 89$ & - & $0 / 057$ & $<0 / 001$ \\
\hline Neurotic - quality of life & $-0 / 52$ & - & $0 / 143$ & $<0 / 001$ \\
\hline immature - quality of life & $-0 / 47$ & - & $0 / 023$ & $<0 / 001$ \\
\hline Cognitive emotion regulation - Alexithymia & $-0 / 47$ & - & $0 / 184$ & $<0 / 001$ \\
\hline Cognitive regulation of negative emotion - alexithymia & $0 / 67$ & - & $0 / 050$ & $<0 / 001$ \\
\hline Cognitive regulation of positive emotion - alexithymia & $-0 / 43$ & - & $0 / 021$ & $<0 / 001$ \\
\hline Defense style - Alexithymia & $-0 / 55$ & - & $0 / 125$ & $<0 / 001$ \\
\hline Developed - Alexithymia & $-0 / 47$ & - & $0 / 043$ & $<0 / 001$ \\
\hline Neurotic - Alexithymia & $0 / 56$ & - & $0 / 173$ & $<0 / 001$ \\
\hline immature - Alexithymia & $0 / 73$ & - & $0 / 167$ & $<0 / 001$ \\
\hline Excitement - quality of life & $-0 / 57$ & - & $0 / 085$ & $<0 / 001$ \\
\hline Defense style - Alexithymia - Quality of Life & - & $-0 / 41$ & $0 / 043$ & $<0 / 001$ \\
\hline Cognitive emotion regulation - alexithymia - quality of life & - & $-0 / 35$ & $0 / 134$ & $<0 / 001$ \\
\hline
\end{tabular}

According to Table 2, the upper and lower confidence intervals for the path of defense styles and quality of life mediated by alexithymia and for the path of cognitive emotion regulation and quality of life mediated by alexithymia were not zero. Since zero was outside this interval, the indirect relationship between the variables in both paths was significant.

Table 2. Indirect relationship of variables in the fit structural model

\begin{tabular}{|c|c|c|c|c|c|c|}
\hline path & data & boot & bias & $\begin{array}{c}\text { Standard } \\
\text { error }\end{array}$ & $\begin{array}{l}\text { Lower } \\
\text { bound }\end{array}$ & $\begin{array}{l}\text { Upper } \\
\text { bound }\end{array}$ \\
\hline $\begin{array}{c}\text { cognitive emotion regulation and quality of life mediated by } \\
\text { alexithymia }\end{array}$ & $0 / 4200$ & $0 / 4300$ & $0 / 0100$ & $0 / 6565$ & $0 / 3198$ & $0 / 5498$ \\
\hline defense styles and quality of life mediated by alexithymia & $0 / 2804$ & $0 / 2817$ & $0 / 0013$ & $0 / 0683$ & $0 / 1659$ & $0 / 4468$ \\
\hline
\end{tabular}

\section{Conclusion}

The aim of present study was to evaluate the relationship between cognitive emotion regulation and defense styles and quality of life mediated by alexithymia in patients with hypertension. Based on the 4 variables studied in this study, the relationship between cognitive emotion regulation and quality of life in these patients was first examined. The results showed a significant relationship between these variables of the study. These results are consistent with those of studies conducted by Martino et al. (2020), Reilly (2018), Talepasand and Mahfar (2018), Zhang, Fan, Sang, \& Sang (2017), Graniri et al. (2017), Vojvodic, Gordana \& Djukic-Dejanovic (2017), Barberis, Cernaro \& Costa (2017), Carvalho, Siqueira, Sousa \& Jardim (2013), Dubey \& Pandey (2013), Hyphantis et al. (2013), Saeidian et al. (2019)), Soltani Nejad (2018), KhodapAnah, Sohrabi, Ahadi \& Taghiloo (2018), Rezaei Nejad et al. (2018), Nargesi, Fathi Ashtiani, Davoodi and
Ashrafi (2018), Besharat et al. (2014), Dehkordi et al. (2013), and Besharat (2012). In explaining the obtained results, it can be stated that alexithymia plays an important role in regulating a person's emotions and as it increases, one's vulnerability to personality disorders, mood disorders such as depression or even physical illnesses increases (Khodapanah et al., 2018).

The results of a study conducted by Dubey \& Pandey (2013) showed that people with alexithymia are more likely to use suppression strategies and less likely to use reappraisal strategies than normal people. Suppression strategies are more closely related to mental and physical health problems, so they are considered maladaptive strategies for regulating emotions. People with impairment in cognitive processing are emotionally and cognitively disturbed because they cannot be perceived and evaluated in the cognitive processing process. This disability disrupts the organization of a person's emotions and 


\section{Monthly Journal of Psychological Science}

cognitions and increases the probability of using neurotic and immature defense styles in stressful situations. These people face stress and stressful conditions through denial and ignorance (considered among neurotic and immature styles) (Granieri et al. 2017). This denial and ignorance of stress by these individuals justifies the positive relationship between alexithymia and neurotic and immature defense styles obtained in this study. Emotion regulation and especially positive strategies in emotion control reduce negative emotions, increase positive emotions and adaptive behavior in people. In other words, the use of adaptive strategies makes a person feel more control of the environment and creates a kind of positive feeling in him or her that not only prevents the person from experiencing emotional problems but also has a positive effect on his or her quality of life (Barberis et al. 2017). Symptoms related to the disease affect a person's physical, mental and social function and reduce his or her quality of life. What is crucial in evaluating the quality of life is the patient's psychological adaptation to the symptoms of the disease. If the patient uses unsuccessful strategies in reducing stress, his or her physical and mental health and consequently his or her quality of life will decrease (Talepasand and Mahfar, 2018).

As a general conclusion, when the processes of recognizing and describing emotions are disrupted for any reason, psychological helplessness closes the ways of logical analysis and thinking and limits the person's cognitive style to objective, pragmatic and realistic thinking. Examples of this cognitive style are the preference of a person with alexithymia just to observe the events and not to analyze and interpret them, to limit their relationships and activities to objective matters, and ignore their own and others' feelings. Besharat (2010) also argues that the cognitive emotion regulation ability is associated with physical, social, mental and physiological health
Vol. 20, No. 108, Winter(March) 2022

consequences and emotion regulation is affected by the ability to recognize, understand and manage emotions or alexithymia. Thus, defense styles cause confusion in a person's emotional system and are directly related to alexithymia. Therefore, patients with hypertension can use cognitive skills to solve problems and overcome alexithymia by applying adaptive cognitive emotion regulation strategies. Also, in the light of mental concentration and emotional calm, it is possible to identify the source of stress and increase the quality of life by recognizing its source of control. Given the relationship between alexithymia and mental health and quality of life, it is recommended to provide training on life skills, especially problem solving skills training for people with alexithymia. Since people with hypertension face problems in alexithymia and emotion regulation, trainings such as emotion regulation, emotional intelligence training, and emotion control training that are effective in reducing emotional problems are recommended for these people.

\section{Ethical Considerations}

Compliance with ethical guidelines: Adherence to the principles of research ethics: The present article was derived from a doctoral dissertation of the first author of the article in the field of health psychology from Kish International Azad University under the code of ethics of IR.HUMS.REC.1399.098. In this study, participants participated in the research consciously and voluntarily.

Funding: The present study was derived from a doctoral dissertation conducted by the first author and it was not financially supported.

Authors' contribution: In the present article, the first author was the principal researcher of the research. The second author was the supervisor and the third author was advisor of the doctoral dissertation.

Conflict of interest: Authors of this article declared no conflict of interest for the present study.

Acknowledgments: We hereby appreciate the supervisors and advisors as well as staffs of Shiraz Heart Hospital who helped us in conducting the present study. 


\title{
بررسى مدل ساختارى رابطه بين تنظيم شناختى هيجان و سبك هاى دفاعى با كيفيت زندكى و با ميانجى كرى ناكويى
}

\section{هيجانى در بيماران مبتلا به فشارخون بالا هيناف}

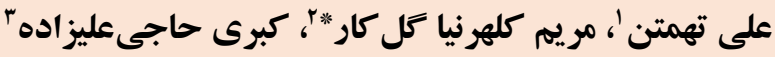

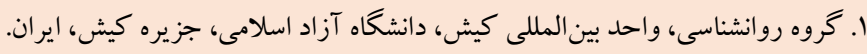

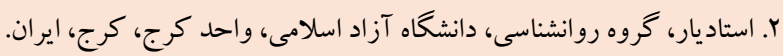

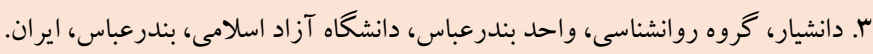

\begin{tabular}{|c|c|}
\hline \multicolumn{2}{|l|}{ زمينه: با توجه به اينكه فشارخون بالا يكى از مهمترين تهديدكنندهاى سلامتروان و كيفيت زندگى به شمار مىرود؛ ازاينرو، بررسى } \\
\hline عوامل مهم روانشناختى همجيون تنظيم شناختى هيجان و سبكك هاى دفاعى مورد استفاده توسط افراد مبتلا به فشار خون بالا و تأثير اين متغيرها & 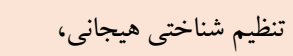 \\
\hline بر كيفيت زندگى آنها، مى تواند در بهبود وضعيت روانشناختى اين بيماران كمك كنده باشد. & 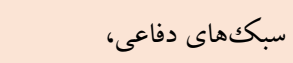 \\
\hline هدف: هدف يُزوهش حاضر، بررسى مدل ساختارى رابطة بين تنظيم شناختى هيجان و سبك هاى دفاعى با كيفيت زندگى با ميانجى گرى & 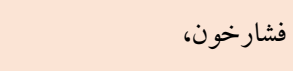 \\
\hline ناخو يى هيجانى در بيماران مبتلا به فشار خون بالا بود. & كيفيت زند \\
\hline روش: يُوهش حاضر توصيفى و از نوع همبستكى و معادلات ساختارى بود. جامعةُ آمارى شامل ل بيمار مبتلا به فشارخون بالا كه در & ناكويى هيجانى \\
\hline 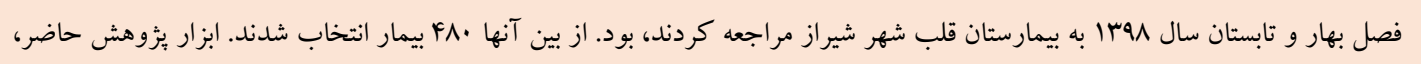 & \\
\hline 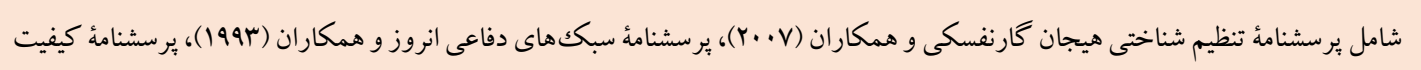 & \\
\hline زندگى سازمان بهداشت جهانى (1999) و يرسشنامة ناكويى هيجانى تورنتو تايلر و همكاران (1994) بود. دادهها با استفاده از آزمون & \\
\hline كلمو كروف اسميرنوف، رگرسيون خطى و مدلسازى معادلات ساختارى با استفاده از نرمافزارهاى SPSS25 و ليزرل N/A تجزيه و تحليل & \\
\hline شد. & \\
\hline يافته ها: متغيرهاى تنظيم شناخت هيجان و سبك هاى دفاعى رابطه معنادارى را با متغير كيف & \\
\hline 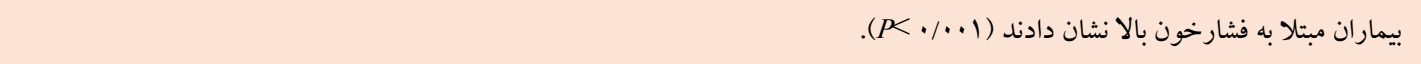 & 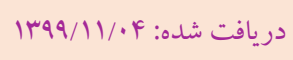 \\
\hline نتيجه كيرى: استفاده از راهبردهاى تنظيم شناختى هيجان و نوع سبككهاى دفاعى براى غلبه بر ناكويى هيجانى توسط افراد مبتلا به فشارخون & 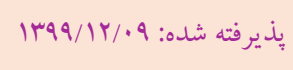 \\
\hline بالا، مى تواند كيفيت زندگى اين افراد را تحت تأثير قرار دهد. & 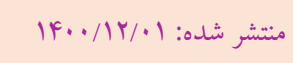 \\
\hline
\end{tabular}

* نويسنده مسئول: مريم كلهرنيا گل كار، استاديار، كروه روانشناسى، دانشخاه آزاد اسلامى، واحد كرج، كرج، ايران. رايانه: maryamgol1986@yahoo.com

تلفن: 
بررسى ها نشان داده است كه هيجانات منفى و مثبت باعث ايجاد ياسخ هاى

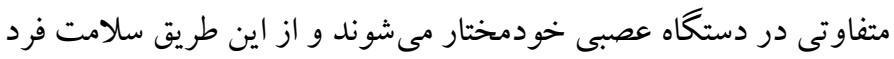

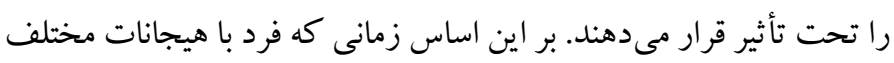

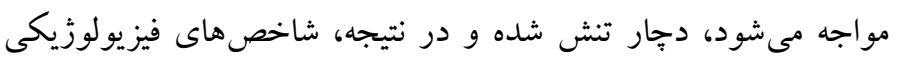
همجون فشار خون، ضربان قلب، تنفس و ترشح برخى هورمونهاى بدن

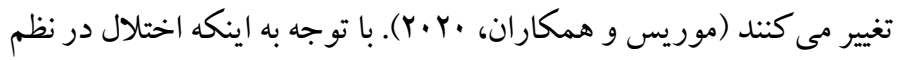
هيجانى و رخدادهاى تنشزا ارتباط معنادارى با شاخص هاى فيزيولوزيكك

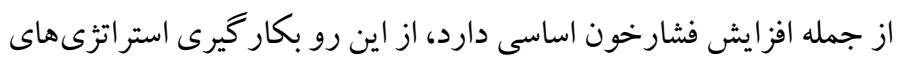

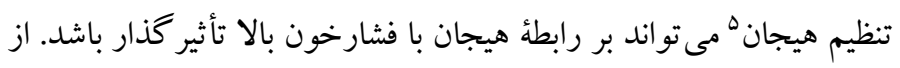

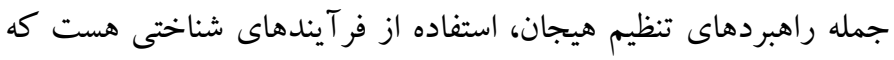

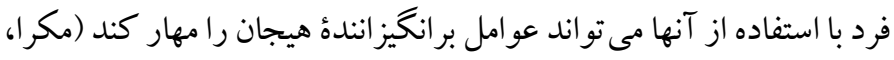

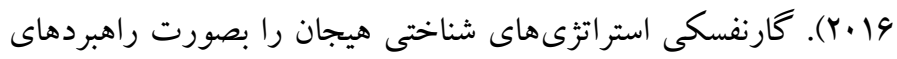

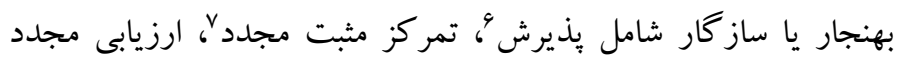

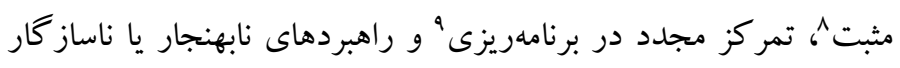
شامل سرزنش خود "، سرزنش ديخران"'، نشخوار فكرى بان و فاجعه آميز

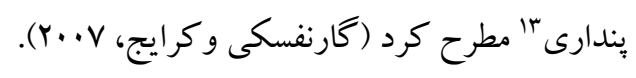

عدم تو انيى در تنظيم هيجانها با مشكلات جسمى و روانى افر ادى كه مبتلا به ناكويى هيجانى (آلكسى تيمياء") هستند، مرتبط است. راهبردهاى تنظيم تونيم

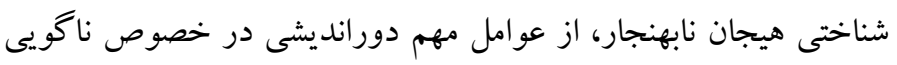

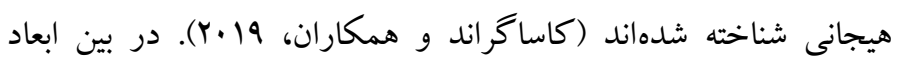

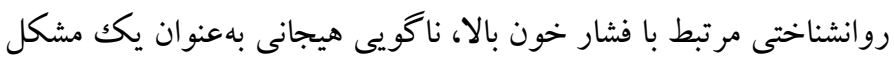

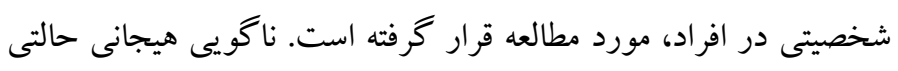

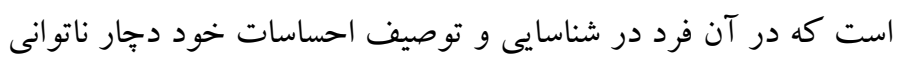

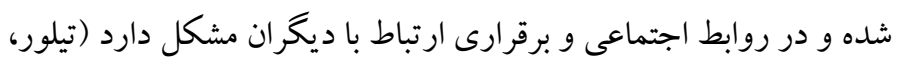

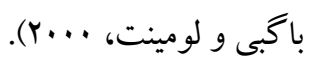
بر اساس تحقيقات انجام گرفته، عواملى همجون جنسيت، سن، ميزان تحصيلات، شغل و موقعيت اجتماعى افر اد در ميزان شيوع ناكويى هيجانى

\footnotetext{
${ }^{8}$. Positive reappraisal

9 . Refocus on planning

10. Self-blame

${ }^{11}$. Blaming others

12. Rumination

13. Catastrophizing

${ }^{14}$. Alexithymia
}

مقلمهه

امروزه در جوامع مختلف، با توجه به تغيير سبك زندكى و افزايش تنشهاى عصبى ناشى از استرس و اضطراب، بيمارىهاى قلبى عروقى نهى

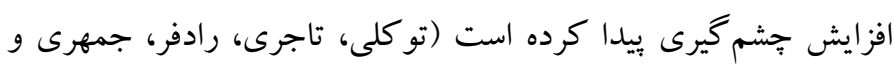

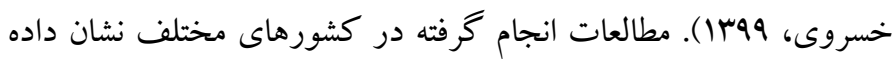

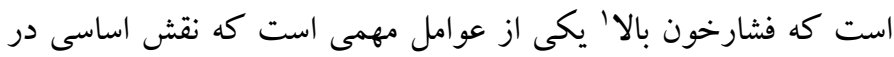

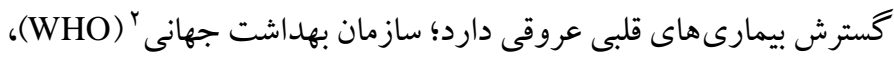

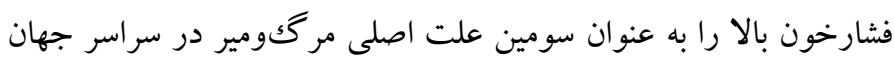

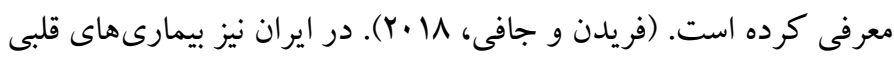

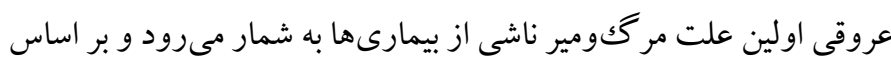

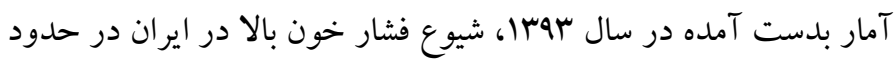


مهدوى روشن، اميدى و عاقبتى، IV (Y).

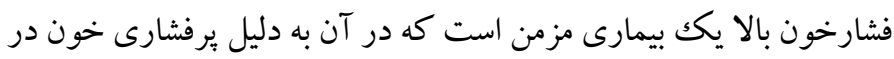

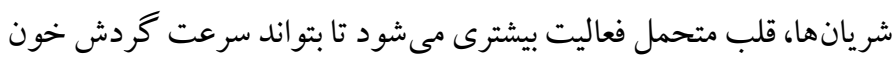

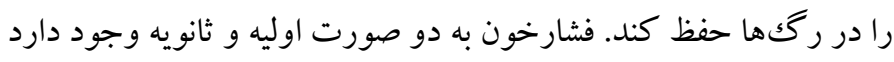

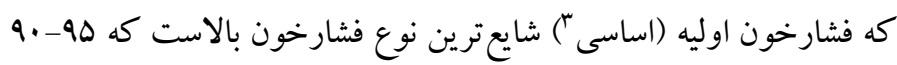

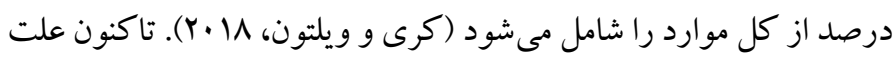
مشخصى براى آن شناخته نشده است، اما اينطور بيان مى مشود كهد كه فشار

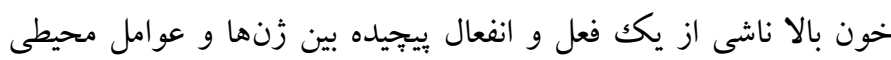

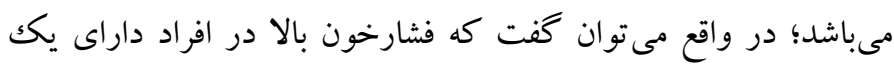

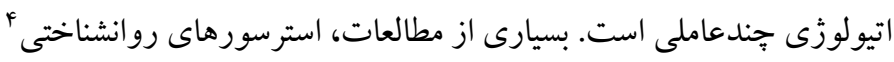
همجيون اضطراب و استرس، عصبانيت، عدم كنترل هيجانات، افسردگى إنى

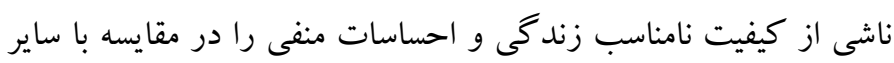
عوامل محيطى، در افزايش و توسعه فشارخون بالا برجسته تر مىدانند

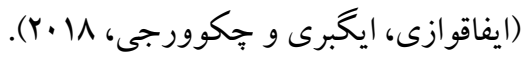

1. High blood pressure

2. Wold Health Organuzation (WHO)

${ }^{3}$. Essential hypertension

${ }^{4}$. Psychological stressors

5 . Emotion regulation strategies

${ }^{6}$. Acceptance

7. Positive refocusing 
مى كند (ريلى، Y (Y). مكانيسمهاى دفاعى مسئول محافظت از من Y را در

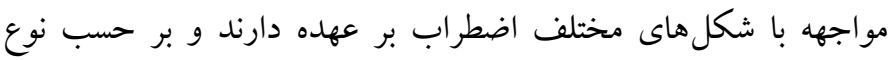

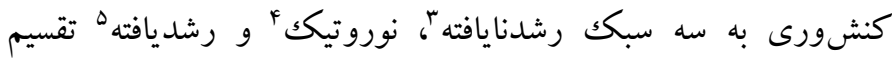
مى شوند. سبكك رشدنايافته به عنو ان مكانيسم وايسرونده محسوب مى شود. دفاعهاى نوروتيك نيز به مؤلفهاى وسواسى و سر كوب تقسيم مىشوند.

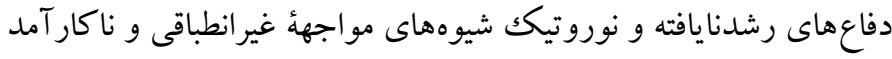

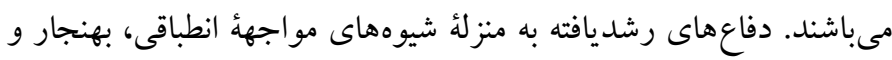

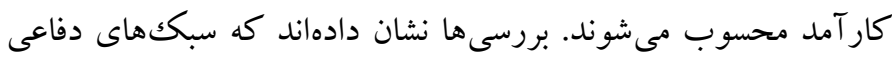

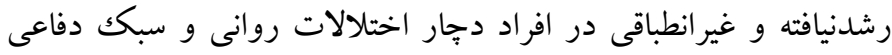

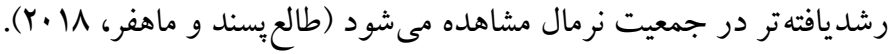

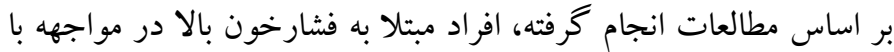

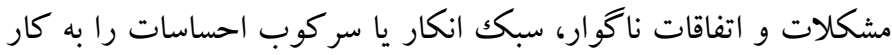
مى گيرند. مكانيسمهاى دفاعى مبتنى بر هيجان، به صورت منفى و سبك نك

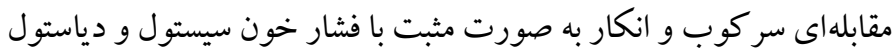
ارتباط معنادارى دارند (دهكردى، صالحى و رضايى، זوبا). در واقع اختلال در سبك هاى دفاعى مى تواند با نارسايى در شناخت و بيان هيجانها همراه شود (جو كار، فرهادى و دلفان بيرانوند، Vqr ).

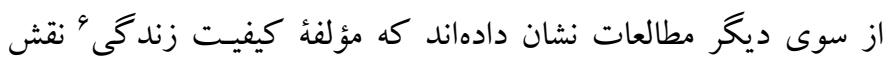
مهمى را در بيشبينى ميزان مكانيسم دفاعى دارد و بالا بودن سطح آن، نشان دهندهُ سلامتى فرد مىباشد. مواردى همجون برجسب بيمارى زدن، تغيير در فعاليتهاى روزانه، ترك شغل، افسردگى، اضطراب، افت عملكرد فيزيكى، عوارض بيمارى و دارو درمانى با ايجاد فشار روانى بر بيماران مبتلا

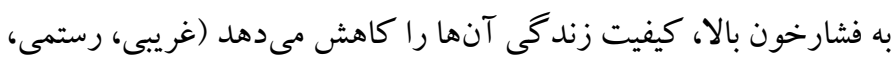
محمديانشريف و منقى، هوس|). به عبارتى، فشارخون بالا با كاهش توانيى هاى جسمانى و ظرفيتهاى فيزيولوزيكك فرد، بر كيفيت زندگى او

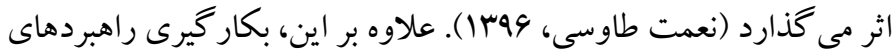

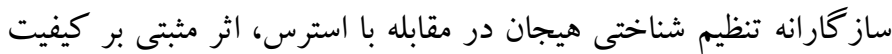

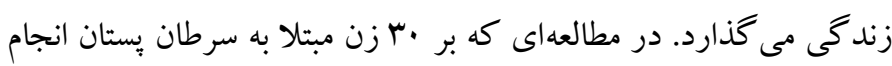

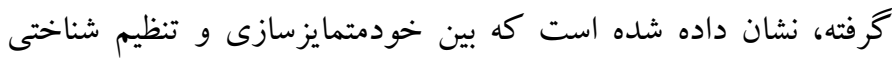

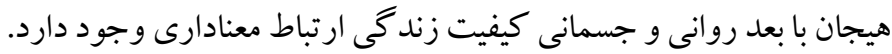

${ }^{4}$. Neurotic

5. Mature

${ }^{6}$. Quality of life
تأثير گذار هستند (بارانزو كى، (Y). بر اساس ئزوهشهاى انجام گرفته بر روى مردم عادى، ميزان بروز ناكويى هيجانى در مردان تقريبا دو برابر زنان

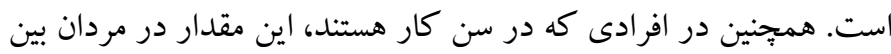
19-V درصد و در زنان ه-· -1 درصد گزارش شده است. از طرفى ميزان

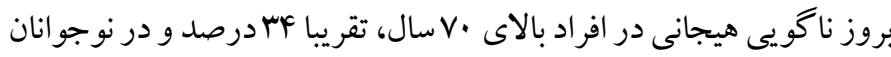
V درصد تخمين زده شده است (سانتورلى و ردى، ها •Y). دركك و بيان احساسات از ويزگگ هاى بسيار مهم در افراد مىباشند؛ مطالعات انجام گرفته بر روى افرادى كه دجار آلكسى تيميا هستند، نشان

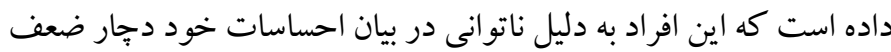
در كنترل تكانها، خشم ناكهانى، بى تفاوتى نسبت به ديخران، حساسيت بالا نسبت به صداها و لمس شدنها، تو انايى پايين در درك احساسات

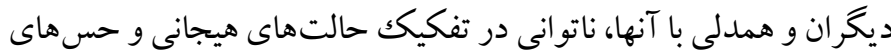

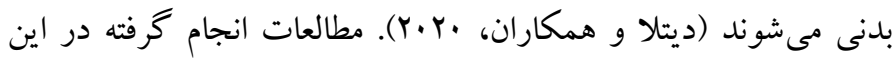
زمينه، نشان داده است كه مبتلايان به ناگويى هيجانى در مقايسه با افراد غيرمبتلا، مشكلات سلامتى بيشترى دارند و در تنظيم هيجانهاى خود با نهان مشكلات بيشترى مو اجه هستند (كاساكر اند و همكاران، 19 •Y). به عبارتى، ناكويى هيجانى موجب مىشود تا فرد با اجتناب از عوامل دردناكك مبتنى

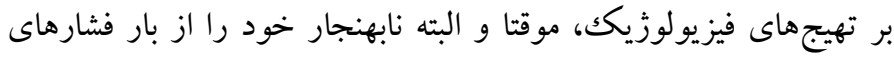
حاصل از عو اطف دردناكك نجات دهد (بلاكى، آبراموويتز، رومان، لئونارد و ريمان، Yl V)؛ در نتيجه او را مسبب ابتلا به بيمارىهايى همبجون قند خون بالا، فشارخون اساسى، نشانگان روده تحريك يذير (يورسلى، ديكارن

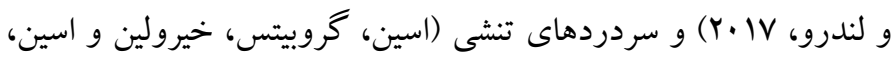
( ) و و غيره مى كند. (Y) در مطالعات ديخرى، ناگويى هيجانى نوعى مكانيسم دفاعى' يا مقابلهاى

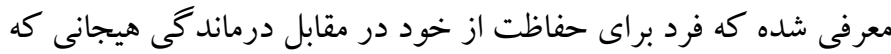
در موقعيتهاى آسيب زننده ايجاد مىشود، بكار مى گيرد (بشارت و

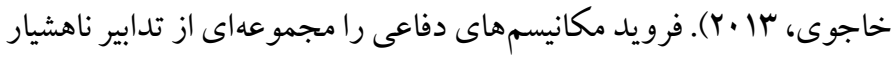

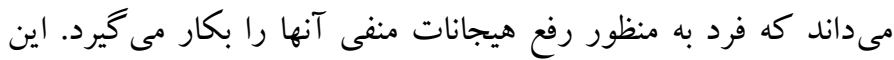
مكانيسمهاى دفاعى كه بر بائه هيجانات هستند، نه تنها باعث تغيير موقعيت

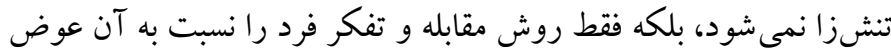

${ }^{1}$. Defensive mechanisms

. Ego

3. Immature 


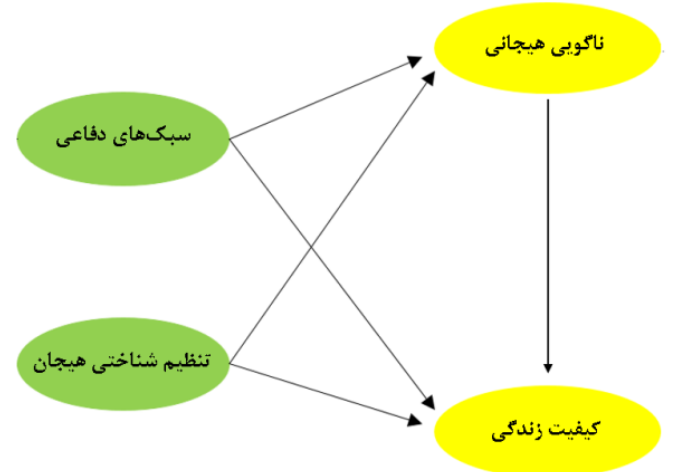

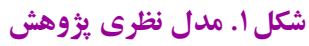

روش

الف) طرح بؤوهش و شر كت كنند كان: يزوهش حاضر توصيفى و از نوع همبستخى و معادلات ساختارى مىباشد. در اين يُزوهش، تنظيم

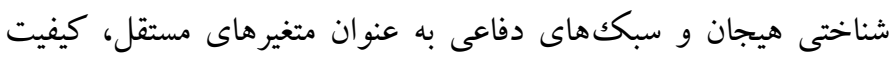

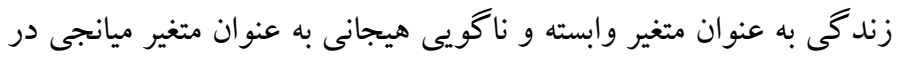

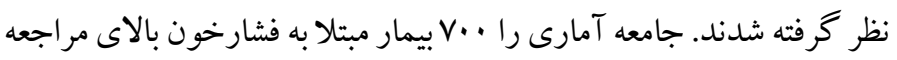

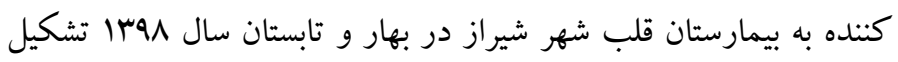

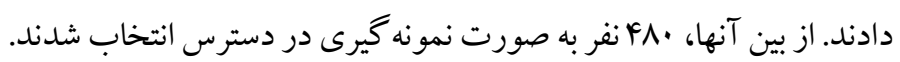
به اين صورت كه با مر اجعه به بيمارستان قلب شهر شيراز با رجوع به بروندهُ

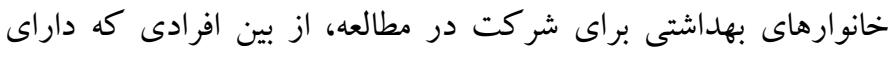

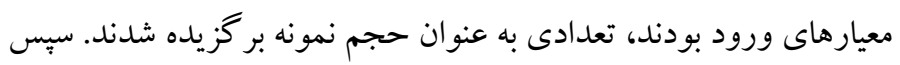
برسشنامه هاى بزوهش توسط افر اد تكميل شد. ملاكك هاى ورود به مطالعه،

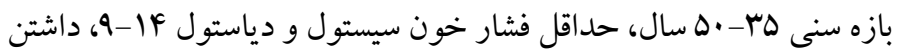
حداقل يكك سال سابقه فشارخون بالا و سواد خواندن و نوشتن بود. معيارهاى خروج از مطالعه، وجود هر نوع بيمارى طبى ديخر و همجنين

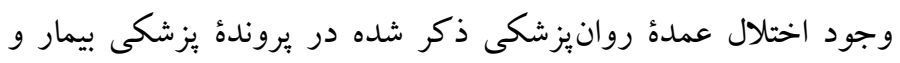
استفاده از داروهاى روانيزشكى بود. قبل از تكميل يرسشنامه، رضايت

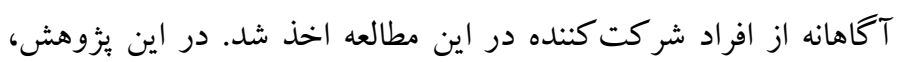
ملاحظات اخلاقى در نظر كرفته شد و به افرادى كه در اين مطالعه حضور داشتند، اين اطمينان داده شد كه اصول رازدارى در خصوص اطلاعات آنها

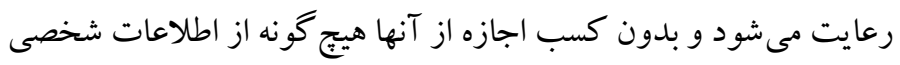
آنها در اختيار كسى قرار نمى كيرد.
در واقع كاهش خودمتمايزسازى بيماران باعث افزايش استفاده از

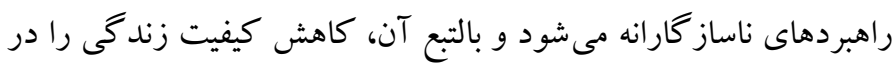

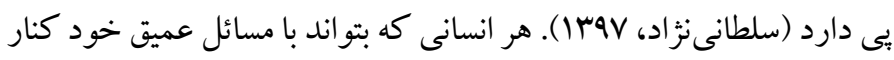
بيايد و در برابر تعارضات اجتنابنايذير درونى خود ناتوان نشود، فردى

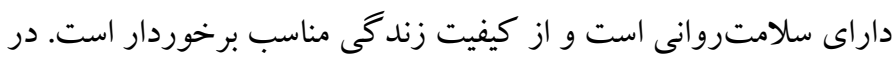
مطالعهاى به منظور بررسى اثربخشى درمان متمركز بر شفقت بر ميزان فشار

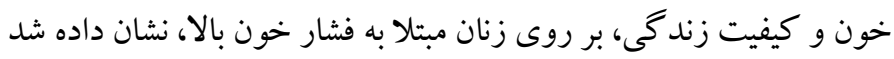

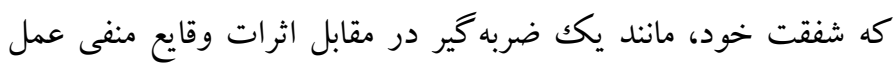

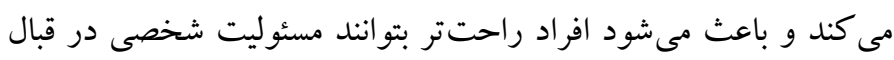

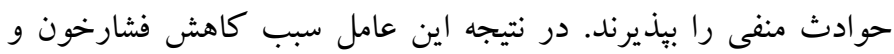

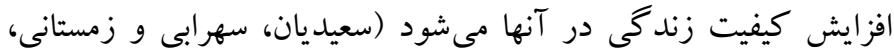

$(1+94$

با توجه به اينكه كيفيت زندگى يكى از مهمترين مؤلفهاى مفهوم كلى

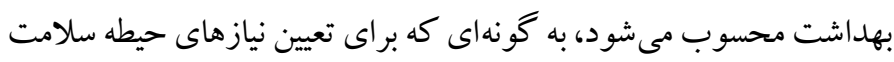

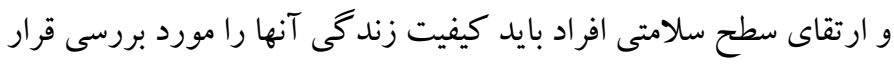
داد. از سوى ديخر، فشارخون بالا يكى از شايعترين و و مهمترين

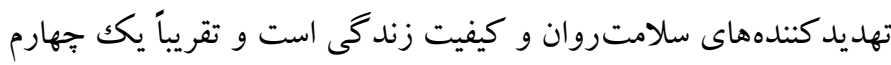

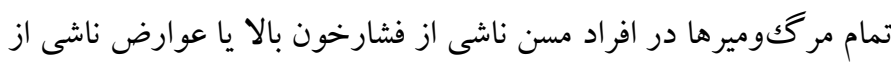

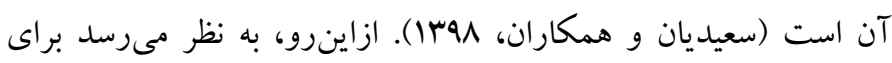

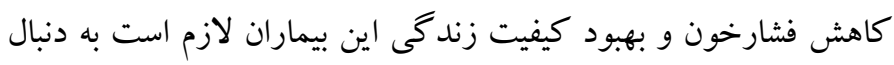

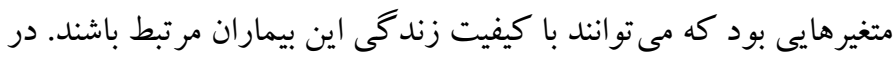

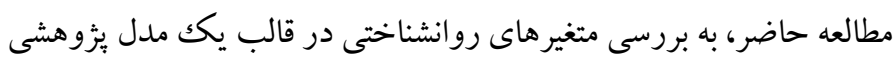

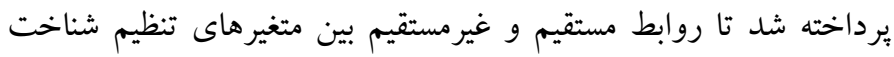

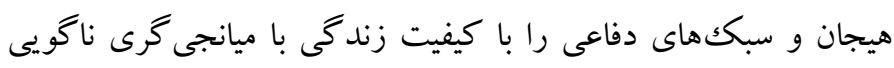

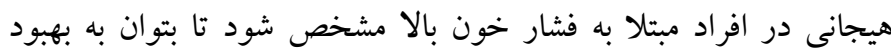
وضعيت روانشناختى بيماران مبتلا به يرفشارى خون كمكك نمود.

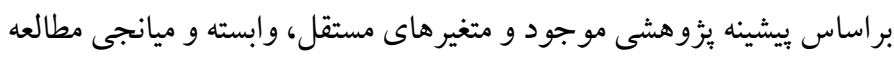

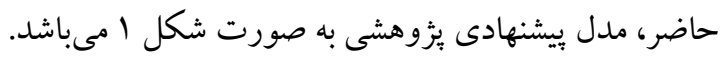


سبكك نوروتيكك از V9/• تا 91/ • گزارش كرد. اين ضرايب، تأييد كنندة همسانى درونى خرده مقياسهاى يرسشنامة سبككهاى دفاعى مىباشد.

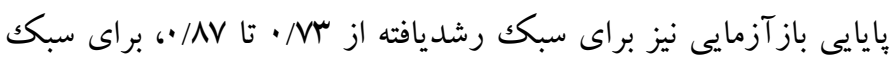

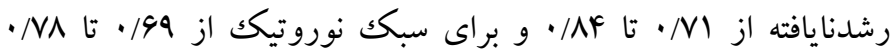

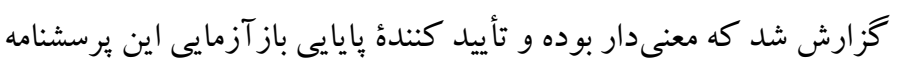
مىباشد.

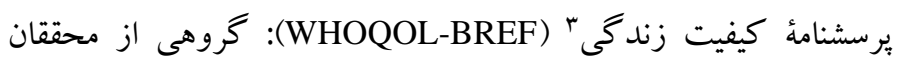

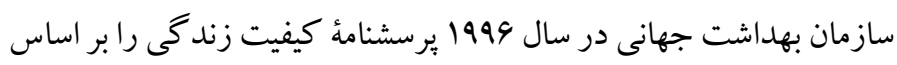
نسخه ..1 سؤالى آن طراحى كردند. اين برسشنامه شامل \& ز زيرمقياس سلامت جسمى، سلامتروان، روابط اجتماعى، سلامت محيط و يكك نمره

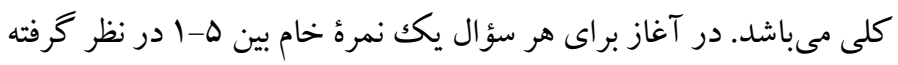

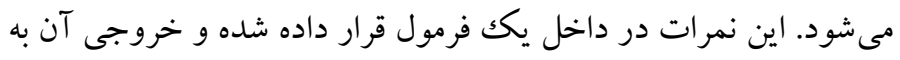
صورت نمرهاى استاندارد شده بين · تا ..1 مىباشد. نمره بيشتر به معناى

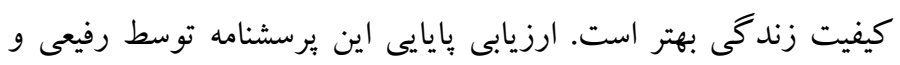

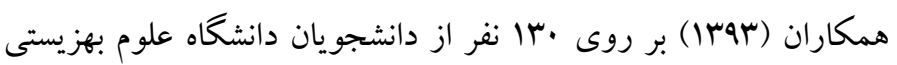

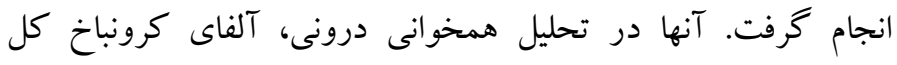

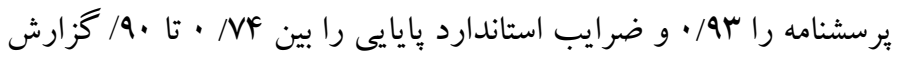

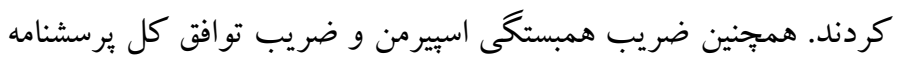

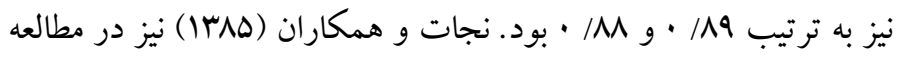
خود، ضريب آلفاى كرونباخ را براى جمعيت سالم در حيطة سلامت

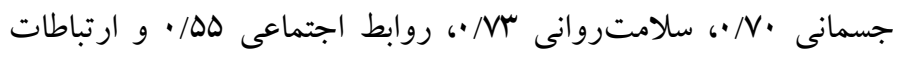

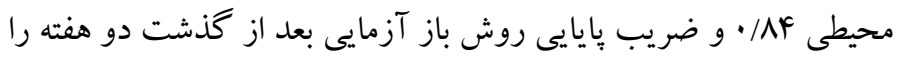

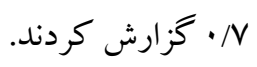

برسشنامة ناكويى هيجانى تورنتو (TAS-20): اين برسشنامه توسط بحتبى،

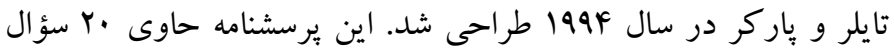
مىباشد كه در آن سه زير مقياس دشوارى در شناسايى احساسات، دشوارى براى توصيف احساسات و تفكر عينى در يكك طيف ينج درجهاى ليكرت

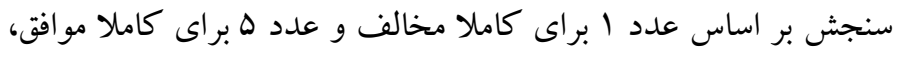
سنجيده مىشود. از مجموع ب خرده مقياس، يكك عدد كل بدست مى آيد.

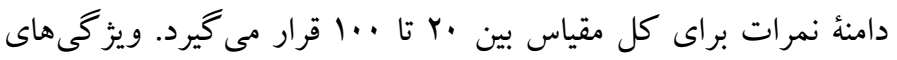

${ }^{4}$. The Toronto Alexithymia Scale-20 (TAS-20)
ب) ابزار برسشنامهُ تنظيم شناختى هيجان' (CERQ): اين برسشنامه توسط كارنفسكى و كرايج در سال V...Pr تهيه شده است كه צץ ماده دارد. ياسخ گويى به سؤالات اين مقياس در يكك طيف ينج درجهاى ليكرت از تقريباً هر زز (1) تا هميشه (ه) نمره گذارى مى شود. بصورت 9 خرده مقياس با دو راهبرد مثبت و منفى مىباشد كه شامل سرزنش خود، نشخوار فكرى، فاجعهانگارى و سرزنش ديخرى كه راهبردهاى منفى تنظيم هيجان را تشكيل مى دهند و راهبردهاى يذيرش، تمركز مجدد به برنامهريزى، تمركز مثبت مجدد، ارزيابى مجدد مثبت و كم اهميت شمارى راهبردهاى ساز كار يا مثبت تنظيم هيجانى را نشان مىدهند. دامنه نمرات بين وب تا •ما قرار دارد. هر جهه نمرهُ كسب شده بالاتر باشد، يعنى آن راهبرد توسط فرد بيشتر استفاده شده است. كارنفسكى پيايايى كل راهبردهاى مثبت، منفى و كل

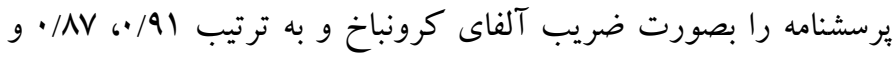

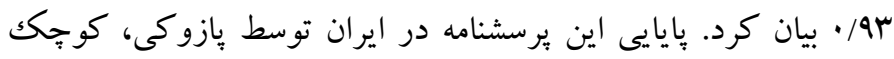
انتظار و قنبرى يناه (F ( ) ارزيابى شد و ضريب آلفاى كرونباخ عامل هاى يرسشنامه را به ترتيب براى سرزنش ديخران سو/.، سرزنش خود 191 •،

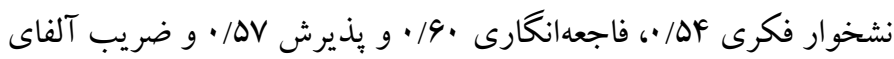

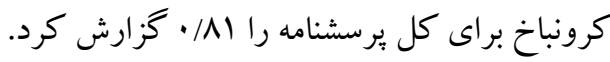

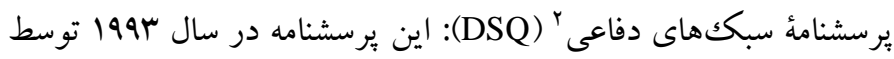
اندروز، سينگ و بوند در قالب . F سؤال طر احى شد. طيف ليكرت آن بين عدد ا (كاملا مخالف) تا عدد 9 (كاملا موافق) نمره گذارى شده است. اين يرسشنامه بر اساس سه زير مقياس سبكك دفاعى رشديافته، نوروتيكك و رشدنايافته، ·r سبك دفاعى را مورد سنجش قرار ميدهد. نمره فرد براى 1. هر يكك از سبككهاى دفاعى، عددى بين Y تا \1 مىباشد. نمره بالایى براى هر كدام از سبككهاى دفاعى به معنى استفاده فرد از آن سبك است. در نهايت در هر سبك، ميانگين نمرات فرد تعيين شده و با نمرهُ ميانگين در سبك هاى ديخر مقايسه مى شود. بيشترين نمره ميانگين نشان دهندهُ استفاده فرد از سبكهاى دفاعى است. بشارت ( اهبا) در يزوهش خود اين يرسشنامه را مورد ارزيابى قرار داد و ضرايب آلفاى كرونباخ را براى سبك

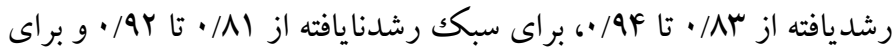

1. Cognitive Emotion Regulation Questionnaire (CERQ)

2. Defense Style Questionnaire (DSQ)

3. World Health Organization Quality of Life Questionnaire 
9-• ال سال و ها| نفر بين ||-ه| سال سابقه بيمارى فشارخون را داشتند. اين آمارهها براى متغيرهاى تنظيم شناختى هيجان، سبككهاى دفاعى، كيفيت زندگى و ناكويى هيجانى محاسبه گرديد. ميانگين تمام متغيرهاى مورد مطالعه بدون در نظركرفتن مقدار انحراف استاندارد تقريبا در حد متوسط بودند (جدول (). به منظور استفاده از اين متغيرها در مدلسازى از

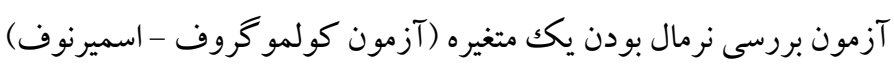
استفاده شد. بر اساس نتايج جدول ب، مقدار احتمال بيشتر از هـ/ • بود؛ تمام متغيرها داراى توزيع نرمال بودند و در نتيجه فرض نرماليتى براى هيج يك از متغيرها رد نشد.

ضريب همبستكى بيرسون، به منظور بررسى عدم وجود رابطة خطى مئى مشتر كك جند گانه بين متغيرها، شدت رابطه و نوع رابطه (مستقيم و معكوس) انجام گرفت. بر اساس مقادير درج شده در جدول سا، ضريب همبستكى بين تمامى متغيرها مثبت و معنادار بود كه نشان دهندهُ وجود رابطه مستقيم بين

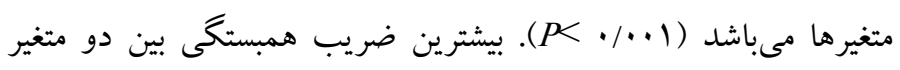
سبك دفاعى و كيفيت زندكى به مقدار ( همبستكى بين دو متغير تنظيم شناختى هيجان و ناخويى هيجانى به مقدار

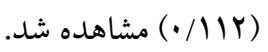

روانسنجى مقياس ناكويى هيجانى تورنتو - · r در ئزوهش هاى متعدد خارجى توسط تيلور، باگبى و لومينت ( . . . ب) بررسى و تأييد شده است. تيلور در مطالعات خود، ضرايب آلفاى كرونباخ را براى ناگويى هيجانى كل (NFF••) و ضريب همسانى درونى را براى ب مقياس دشوارى در تشخيص احساسات (س//)، دشوارى در توصيف احساسات (VD/•) و تفكر عينى (NY/ •) كزارش كرد كه يايايى رضايتبخشى را نشان مى دهد. در نسخه فارسى ناكويى هيجانى تورنتو - ·r نيز يايايى اين برسشنامه بررسى شده و ضريب آلفاى كرونباخ براى ناخويى هيجان كل (هد/•) و براى سه زير مقياس دشوارى در تشخيص احساسها (AY/•)، دشوارى در توصيف احساس ها (VD/•) و تفكر عينى (VY •/) محاسبه شده است كه نشان دهندة

$$
\text { همسانى درونى خوب مقياس بود (بشارت، بوسات ). }
$$

إفتهن

Tارههاى توصيفى جمعيت شناختى اين بثزوهش، از ·FA نفر، YFA نفر مرد

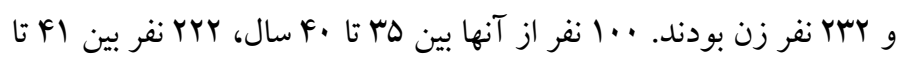

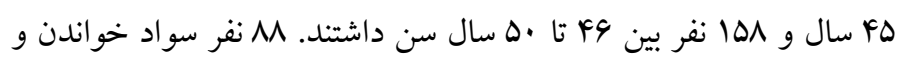

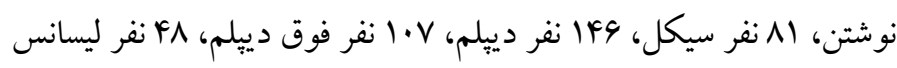

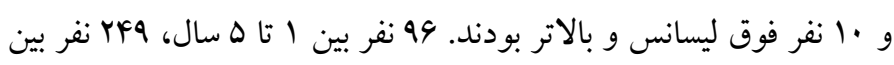

\begin{tabular}{|c|c|c|c|c|c|}
\hline كشيدگى & جولى & انحر اف معيار & ميانگين & تعداد & متغير \\
\hline.$/ .9 F$ & $1 / \cdot \mu 1$ & $\cdot / A 94 \cdot \Delta$ & $r / 11 \cdot V$ & rA. & تنظيم شناخت هيجان \\
\hline.$/ 119$ & $1 / \cdot V r$ &.$/ 91910$ & $r / \cdot r \mu$. & rA. & تنظيم شناخت هيجان مثبت \\
\hline - &.$/ 4 \Delta$ & $\cdot / \Lambda r V \cdot \Lambda$ & $r / l 94 F$ & FA. & تنظيم شناخت هيجان منفى \\
\hline IY/DYF & .1 .49 & - /AYMAI & r/MNIr & FA. & سبك هاى دفاعى \\
\hline$-1 / \cdot r q$ & . & $1 / 1.9 \pi r$ & T/YYYV & FA. & سبك هاى رشد نايافته \\
\hline.$- / 490$ & $\cdot / v 99$ &.$/ Q \wedge 1 \Delta F$ & $r / . r r q$ & rA. & سبك هاى نورو تيك \\
\hline$\cdot / r q$. & $-\cdot / F \Delta V$ & $\cdot / 4 \cdot \Delta \Delta r$ & r/rAr. & FA. & سبك هاى رشد يافته \\
\hline - MYG & $-\cdot / A F$ & - /rVrgV & r/qru. & $\forall \wedge$. & ناكويى هيجانى \\
\hline . r r &.$- / 499$ &.$/ 4199$. & $r / 9911$ & rA. & دشوارى در شناسايى احساسات \\
\hline$-\cdot / 4+1$ & $-\cdot / r \Delta$ & $\cdot / 49 \Delta V V^{F}$ & r/Mfar & FA. & دشوارى در توصيف احساسات \\
\hline$-\cdot / 1 \cdot 1$ & $\cdot / 490$ & $\cdot$ /rArIA & $r / r \Delta \wedge q$ & $r \wedge$. & تفكر عينى \\
\hline$-1 / \cdot v r$ & $\cdot /$ MrF & $1 / .9499$ & r/rQ৭৭ & $\forall \wedge$. & كيفيت زندگى \\
\hline$-1 / M A r$ & - MFF & $1 / 10 \cdot 9$ & $\mu / \mu \cdots q$ & rA. & بعد جسمانى \\
\hline$-1 / 1 r$. &.$/ 494$ & $1 / r 1901$ & r/NAS & rA. & 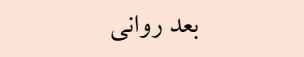 \\
\hline$-\cdot / 9 \cdot 1$ & $\cdot / N F V$ & $1 / \cdot 1919$ & $r / r 1 \cdot 1$ & FA. & بعد روابط اجتماعى \\
\hline$-\cdot /$ A $\wedge$ & $\cdot 19 \cdot r$ & $\cdot / 9 V I A V$ & T/MFYG & $\forall \wedge$. & بعد محيط اجتماعى \\
\hline
\end{tabular}


جدول ז. نتايج آزمون كولموكروف اسميرنوف متغير هاى ثخوهش در كروه نمونه

\begin{tabular}{|c|c|c|c|c|c|}
\hline سطح معنادارى & آماره آزمون & انحراف معيار & 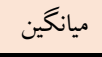 & زيرمقياس ها & عامل كلى \\
\hline.$/ 1 \cdot 1$ &.$/ 119$ &.$/ 9191$ & $r / . r \mu$. & تنظيم شناخت هيجان مثبت & \multirow{4}{*}{ تنظيم شناخت هيجان } \\
\hline.$/ .91$ & $\cdot / / Y \wedge$ & ./ArV. & r/l9AF & تنظيم شناخت هيجان منفى & \\
\hline.$/ 194$ & . / IFY & $\cdot / 4199$ & $r / 9911$ & دشوارى در شناسايى احساسات & \\
\hline.$/ 1 \wedge 9$ & ./1ra & $\cdot / 49 \Delta \mathrm{V}$ & r/mfar & دشوارى در توصيف احساسات & \\
\hline.$/ 100$ & $\cdot / 194$ & $\cdot /$ rArI & $r / r \Delta \wedge q$ & تفكر عينى & \multirow{2}{*}{ ناكويى هيجانى } \\
\hline$\cdot / \cdot 1$ & $\cdot / 10 \wedge$ & $1 / 1.94$ & r/rrgV & رشد نايافته & \\
\hline.$/ 190$ & $\cdot / 1 \cdot 1$ &.$/ 9110$ & $r / . r r q$ & 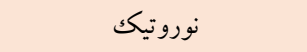 & \multirow{4}{*}{ سبك هاى دفاعى } \\
\hline$\% \cdot v a$ & $\cdot /|r|$ & $\cdot / 4 \cdot \Delta \Delta$ & r/YAF. & ر مشد يافته & \\
\hline.$/ 199$ & / MAr & $1 / 10 \cdot 9$ & $r / r \cdots q$ & بعد جسمانى & \\
\hline.$/ 1 V 9$ & ./Iro & $1 / r 190$ & r/INAr & 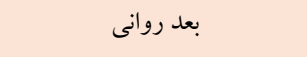 & \\
\hline$\cdot /$ /Ar & $\cdot / / Y \wedge$ & $1 / \cdot \wedge 11$ & $r / r 1 \cdot 1$ & بعد روابط اجتماعى & \multirow[t]{2}{*}{ كيفيت زندگى } \\
\hline.$/ 199$ & . & $\cdot / 9 V 11$ & r/rkre & بعد محيط اجتماعى & \\
\hline
\end{tabular}

جدول r. ماتريس همبستغى سازه متغيرها و مؤلفه هاى آنها

\begin{tabular}{|c|c|c|c|c|c|}
\hline & & تنظيم مثبت & تنظيم منفى & تنظيم شناختى هيجان & 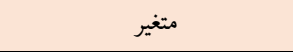 \\
\hline & & & & $1 / \cdots$ & تنظيم شناختى هيجان \\
\hline & & & $1 / \cdots$ & $\cdot / \mu V$ & تنظيم منفى \\
\hline & & $1 / \cdots$ & ./Qr & $\cdot / 89$ & تنظيم مثبت \\
\hline محيط اجتماعى & روابط اجتماعى & بعد روانى & بعد جسمانى & كيفيت زندگى & \\
\hline \multirow{20}{*}{$1 / \cdots$} & & & & $1 / \cdots$ & كيفيت زندگى \\
\hline & & & $1 / \cdots$ & $\cdot 194$ & بعد جسمانى \\
\hline & & $1 / \cdots$ & $\cdot / \Delta r$ & $\cdot 19$ & 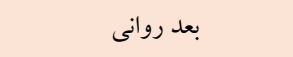 \\
\hline & $1 / \cdots$ & $\cdot 19$ & $\cdot / \Delta r$ & $\cdot / \Delta \mathrm{V}$ & بعد روابط اجتماعى \\
\hline & $\cdot / \Delta 9$ & $\cdot / \Delta \Lambda$ &.$/ 81$ & $\cdot / \Delta \Delta$ & بعد محيط اجتماعى \\
\hline & تفكر عينى & توصيف احساسات & شناسايى احساسات & ناگويى هيجانى & \\
\hline & & & & $1 / \cdots$ & نا نويى هيجانى \\
\hline & & & $1 / \cdots$ & $\cdot / N Q$ & دشوارى در شناسايى احساسات \\
\hline & & $1 / \cdots$ & .194 & $\cdot / N r$ & دشوارى در توصيف احساسات \\
\hline & $1 / \cdots$ & $\cdot / \Delta 9$ & $\cdot 19$ & $\cdot / v$ & تفكر عينى \\
\hline & ر كديافته & نوروتيك & ر رشد نايافته & سبك دفاعى & \\
\hline & & & & $1 / \cdots$ & سبك دفاعى \\
\hline & & & $1 / \cdots$ & $\cdot 191$ & ر رشد نايافته \\
\hline & & $1 / \cdots$ & $\cdot / \Delta r$ & $\cdot 19$ & 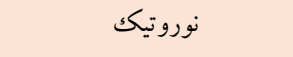 \\
\hline & $1 / \cdots$ & $\cdot 19$ & $\cdot / \Delta r$ & $\cdot / \Delta \mathrm{V}$ & ر ت كديافته \\
\hline & كيفيت زندگى & ناخويى هيجانى & سبك دفاعى & تنظيم شناختى هيجان & \\
\hline & & & & $1 / \cdots$ & تنظيم شناختى هيجان \\
\hline & & & $1 / \cdots$ & - /ArV & سبك دفاعى \\
\hline & & $1 / \cdots$ & $\cdot / 011$ & $\cdot / 11 r$ & ناكويى هيجانى \\
\hline & $1 / \cdots$ & $\cdot / 41 \Lambda$ & .1944 & - /Ora & كيفيت زندگى \\
\hline
\end{tabular}




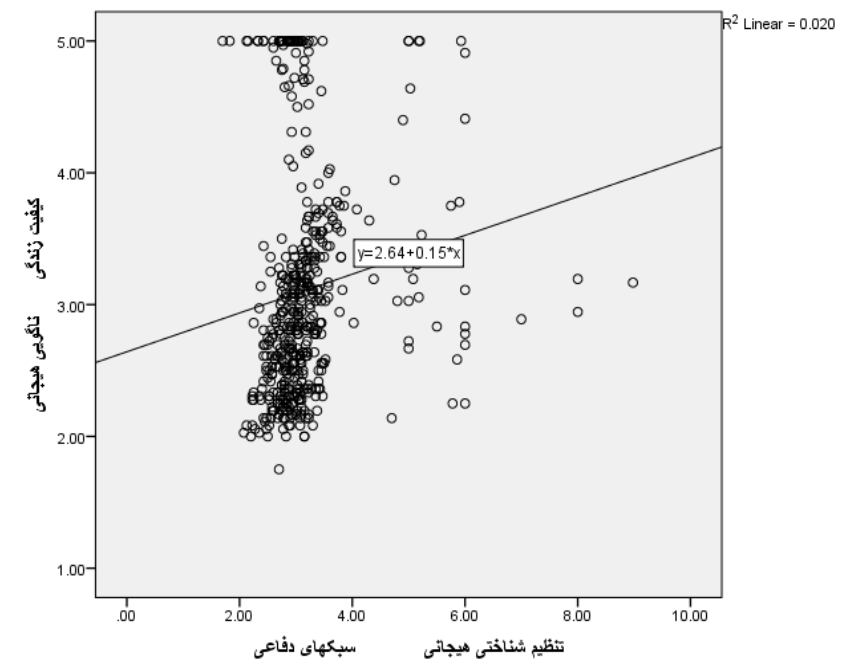

شكل r. ير اكند كى دادهها با آزمون باكس ويسكر

در ادامه به تحليل مدل ساختارى (SEM) يُداخته شد (شكل ؟). ابتدا

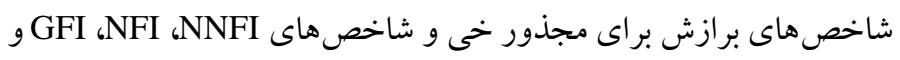
محاسبه شد. طبق جدول FCFI ميزان RMSEA نزديك به صفر بود. مقادير ساير شاخصهاى برازش

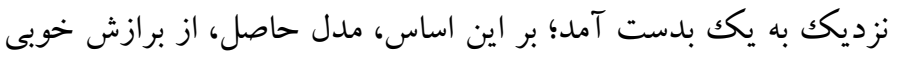

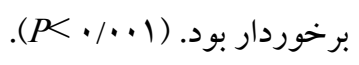

براى بررسى روايى واگرا از ماتريس حاوى مقادير ضرايب همبستخى بين سازهها و جذر مقادير AVE مربوط به هر سازه استفاده شد. نتايج نشان داد ركري كه جذر AVE هر سازه از ضريب همبستكى آن سازه با سازههاى ديخر بيشتر است كه اين مطلب حاكى از قابل قبول بودن روايى واكراى سازه ها مىباشد. براى تعيين شدت تأثير متغير ميانجى، از آماره واريانس محاسبه شده

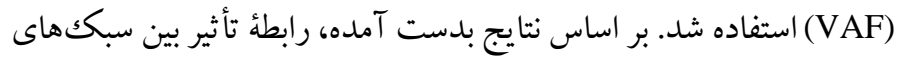

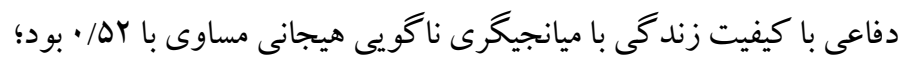

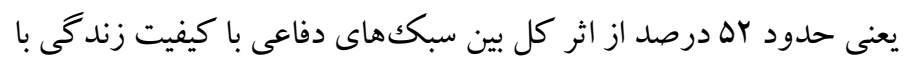
ميانجى گرى ناكويى هيجان تبين شد. همبجنين تأثير بين تنظيم شناختى

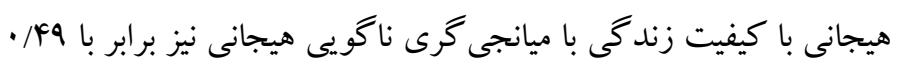

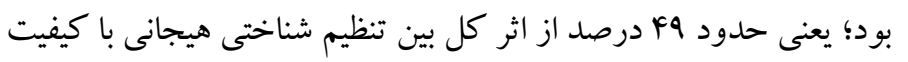
زندگى با ميانجى گرى ناكويى هيجانى تبيين شد. مقدار آمارهُ دوربين

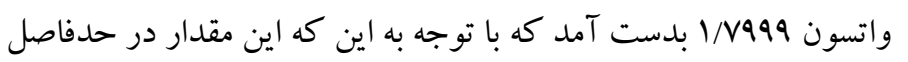

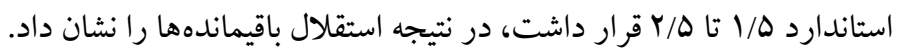

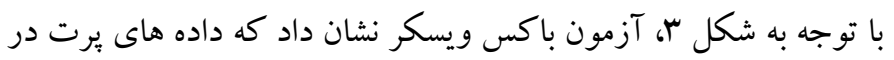
اين تحقيق كم بود و در نتيجه تحقيق هيج تأثير منفى نداشته است.

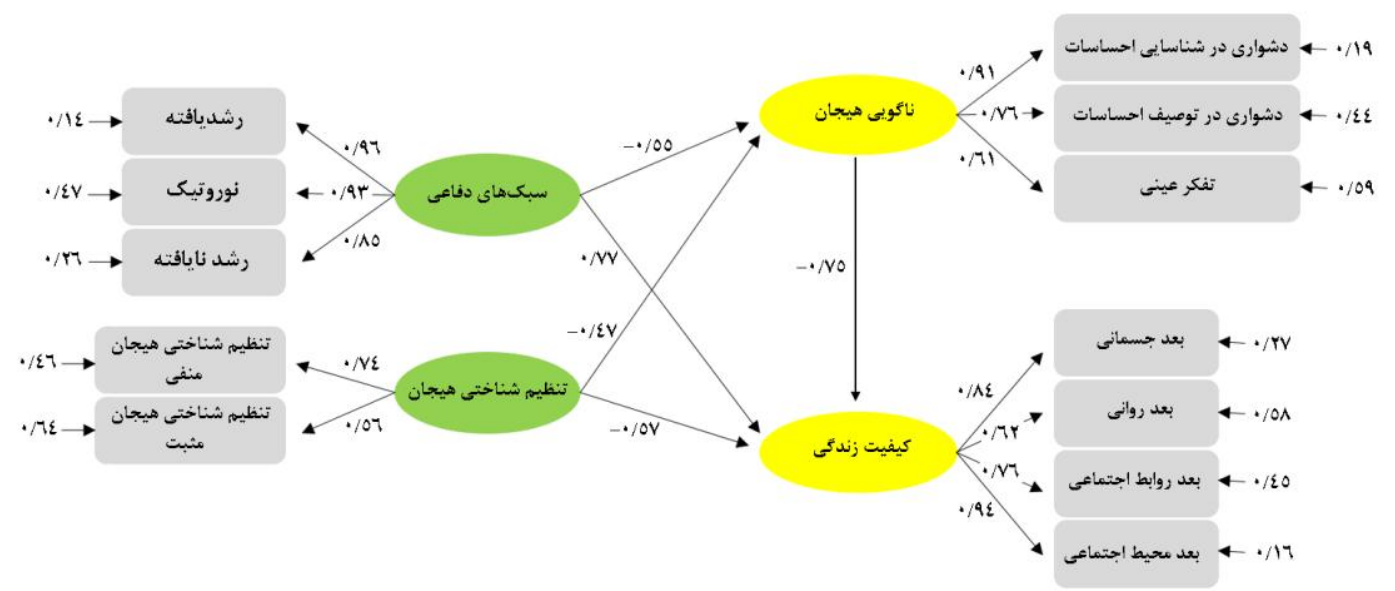

شكل r. مدل ساختارى برازش شده در تبيين رابطة ساختارى متغيرها

جدول ع. شاخص هاى نيكويى بر ازش مل ل ساختارى

\begin{tabular}{|c|c|c|c|c|c|c|c|c|}
\hline مقدار احتمال & NNFI & NFI & RMSEA & GFI & CFI & $\chi^{2} \mathrm{ldf}$ & $\chi^{2}$ & متغير \\
\hline$<\cdot / \cdots)$ &.$/ 91$ &.$/ 9 F$ & $.1 \cdot \mathrm{V}$ &.$/ 9 r$ &.$/ 94$ & $r / 99$ & $r V W / V$ & تنظيم شناخت هيجان \\
\hline
\end{tabular}


متوسط و معنادار و بين تنظيم شناختى هيجان مثبت با كيفيت زندكى رابطه مثبت و قوى و معنادارى مشاهده شد. بين متغير ناكويى هيجان با كيفيت زندگى نيز رابطهُ منفى و قوى و معنادارى وجود داشت. از نتايج حاصل اينطور نتيجه كيرى شد كه رابطة بين متغيرهاى تنظيم شناختى هيجانى و سبكك هاى دفاعى با متغير كيفيت زندكى با ميانجى گرى ناكويى هيجانى در بيماران مبتلا به فشارخون بالا، معنىدار بود

$$
(P<\cdot 1 \cdot 1)
$$

با توجه به جدول و، حد بالا و يايين فاصله اطمينان براى مسير سبك هاى

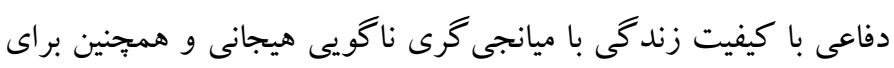
مسير تنظيم شناختى هيجانى با كيفيت زندگى با ميانجى گرى ناكويى هيجانى صفر را در بر نخرفت. با توجه به اينكه صفر بيرون از اين فاصله قرار داشت، رابطه غير مستقيم بين متغيرها در هر دو مسير، معنى دار بود.
بر اساس نتايج جدول ه، ضريب استادارد بين مؤلفه هاى سبكك دفاعى رشد نايافته و نوروتيك با متغير كيفيت زندكى عددى منفى و بين س/ • تا 9 • بلدست آمد كه نشان دهندهُ رابطه منفى، متوسط و معنادار بين اين متغيرها بود. در مقابل، ضريب استادارد بين مولفهُ سبك دفاعى رشديافته با كيفيت زندكى عددى مثبت و بزرگكتر از / / · بدست آمد كه نشان دهندهُ رابطه مثبت، قوى و معنادار بين اين متغير ها بود. بر همين اساس، بين تنظيم شناختى هيجان منفى و ناكويى هيجان رابطه مثبت، قوى و معنادار و بين تنظيم شناختى هيجان مثبت و ناخويى هيجانى رابطه منفى، قوى و معنادارى مشاهده شد. رابطة بين مؤلفههاى سبك دفاعى رشديافته و نورو تيكك با متغير ناخويى هيجانى مثبت، متوسط و معنادار و بين سبكك دفاعى رشدنايافته با ناخويى هيجانى منفى و متوسط و معنادار بود. همجين بين تنظيم شناختى هيجان منفى با كيفيت زندگى رابطة منفى و

جدول ه. ضرايب مسير مستقيم و غير مستقيم بين متغيرهاى يخوهش

\begin{tabular}{|c|c|c|c|c|}
\hline مقدار احتمال & خطاى معيار & ضرايب استاندارد مسير غير مستقيم & ضرايب استاندارد مسير مستقيم & متغير \\
\hline$<\cdot / \cdot 1$ &.$/ . k Y$ & - & $-\cdot / \Delta V$ & تنظيم شناخت هيجان - كيفيت زندكى \\
\hline$<\cdot / \cdot \cdot 1$ & $\cdot / 109$ & - & $-\cdot / F V$ & تنظيم شناختى هيجان منفى - كيفيت زندگى \\
\hline$<\cdot / \cdot 1$ & $\cdot /$ /rr & - & $\cdot / \mathrm{Vq}$ & تنظيم شناختى هيجان مثبت - كيفيت زندكى \\
\hline$<\cdot / \cdot \cdot 1$ &.$/ \cdot 1 f$ & - & $\cdot / \mathrm{MV}$ & سبك هاى دفاعى - كيفيت زندگى \\
\hline$<\cdot / \cdot \cdot 1$ & $\cdot / \cdot \Delta V$ & - & $\cdot / \wedge 9$ & رشديافته - كيفيت زندگى \\
\hline$<\cdot / \cdot \cdot 1$ &.$/ \mathrm{kT}$ & - & $-\cdot / \Delta r$ & نوروتيك - كيفيت زندگى \\
\hline$<\cdot / \cdot \cdot 1$ & $\% r r$ & - & $-\cdot / \& V$ & رشد نايافته - كيفيت زندگى \\
\hline$<\cdot / \cdot \cdot 1$ & $\cdot /$ /AF & - & $-\cdot / \& V$ & تنظيم شناختى هيجانى - ناكو يى هيجانى \\
\hline$<\cdot / \cdot \cdot 1$ &.$/ . \Delta$ & - & $.19 \mathrm{~V}$ & تنظيم شناختى هيجان منفى - ناكويى هيجانى \\
\hline$<\cdot / \cdot \cdot 1$ & $\cdot / \cdot r \mid$ & - & $-\cdot / 4 r$ & تنظيم شناختى هيجان مثبت - نا گويى هيجانى \\
\hline$<\cdot / \cdot 1$ & $\cdot /$ Tro & - & $-\cdot / \Delta \Delta$ & سبكك هاى دفاعى - ناكو يى هيجانى \\
\hline$<\cdot / \cdot \cdot 1$ &.$/ .4 r$ & - & $-\cdot / \& V$ & رشديافته - ناكويى هيجانى \\
\hline$<\cdot / \cdot \cdot 1$ & $\cdot / \mathrm{IVr}$ & - & $\cdot / \Delta 9$ & نوروتيك - ناكويى هيجانى \\
\hline$<\cdot / \cdot \cdot 1$ &.$/ 19 \mathrm{~V}$ & - & $\cdot / v r$ & رشد نايافته - ناكو يى هيجانى \\
\hline$<\cdot / \cdot 1$ & $\cdot / \cdot \wedge \Delta$ & - & $-\cdot / V \Delta$ & ناكويى هيجان - كيفيت زندگى \\
\hline$<\cdot / \cdot \cdot 1$ &.$/ \cdot \mathrm{kr}$ & $-\cdot / 41$ & - & سبك هاى دفاعى - ناكويى هيجانى - كيفيت زندگى \\
\hline$<\cdot / \cdot 1$ & $\cdot / M F$ & 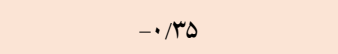 & - & تنظيم شناختى هيجانى - ناكويى هيجانى - كيفيت زندگى \\
\hline
\end{tabular}

جدولآ. رابطه غير مستقيم متغير ها در مدل ساختارى بر ازش شده

\begin{tabular}{|c|c|c|c|c|c|c|}
\hline 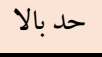 & حد بايين & خطاى معيار & 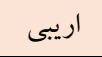 & 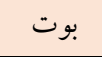 & داده & مسير \\
\hline.$/ 0 F 9 \Lambda$ & $\cdot / / 191$ & .19090 & $\cdot / \cdot 1 \cdots$ & $. / 4 r .$. & $\cdot / 4 r \ldots$ & تنظيم شناختى هيجانى با كيفيت زندگى با ميانجى گرى ناكويى هيجانى \\
\hline.$/ F \notin 91$ &.$/ 1909$ &.$/ .91 \mu$ & •/../r & $\cdot$ /YNIV & $\cdot / r \Lambda \cdot F$ & سبك هاى دفاعى با كيفيت زندگى با ميانجى گرى ناگويى هيجانى \\
\hline
\end{tabular}


نتيجه ناراحتى و تنيدگى كمترى را تجربه كرده و به راحتى با آن رويداد كنار بيايند.

سبس ارتباط بين سبككهاى دفاعى با كيفيت زندگى در بيماران مبتلا به

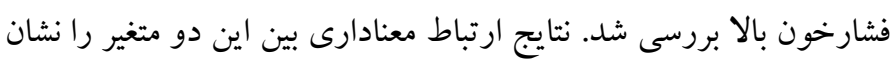

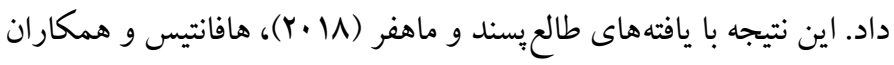

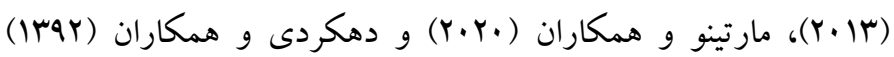
همخوانى داشت. اين نتايج را مى توان به شرح زير تبيين كرد.

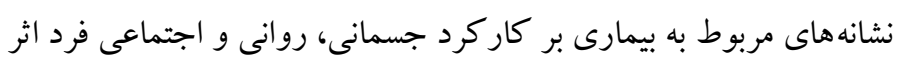

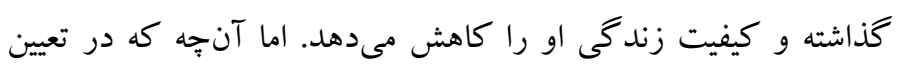
كيفيت زندگى از اهميت بالايى برخوردار است، تطابق بيمار از نظر

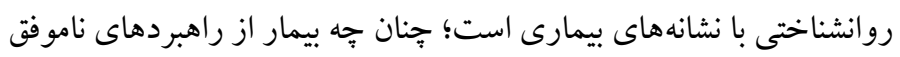
در كاهش استرس استفاده نمايد، سلامت جسمانى و روانى و در نتيجه

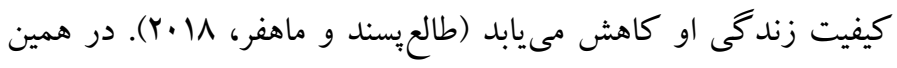

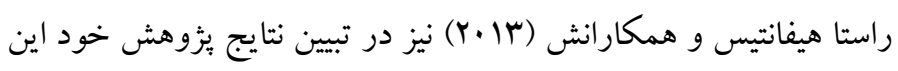

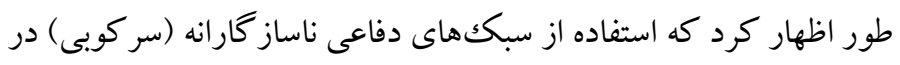
برابر مسائل زندگى با ميزان آسيبهاى روانشناختى و جسمى رابطه

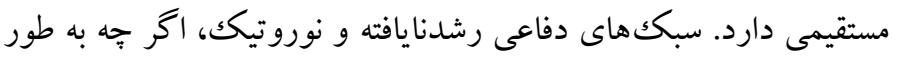

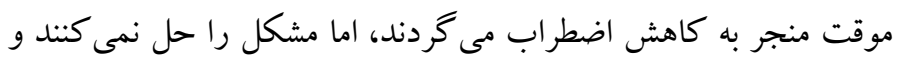
شيوه مناسبى براى كنار آمدن و يذيرش مشكل ارائه نمىدهند. در نتيجه،

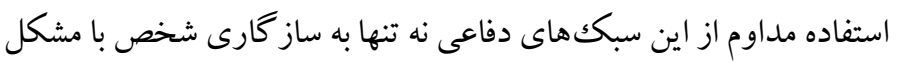
كمكى نمى كنند، بلكه سبب افزايش مشكلات هيجانى و اثرات منفى بر وضعيت سلامتى فرد مى گردند. سبككهاى دفاعى به خصوص سبك سبك هاى رشدنايافته تر، مانعى براى درك واقعيت در فرد شده و امكان دفاع منطقى فردي و مؤثر را از وى سلب مى كنند. همجنين ظرفيت بينشى و خوداكتشافى فرد

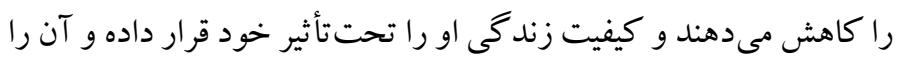
كاهش مىدهند (مارتينو و همكاران، ·.Y.Y). از آنجايى كه سبككهاى دفاعى، تحريف كننده واقعيت هستند، در نتيجه استفاده بيش از حد از سه سبكك دفاعى به منظور كاهش اضطراب، مى تو اند عاملى در بروز مشكلات روانشناختى و بيمارىهاى جسمى، از جمله بيمارىهاى قلبى - عروقى و فشارخون شود (دهكردى و همكاران، بrar ا).

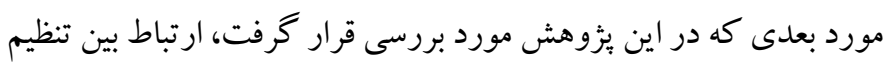
شناختى هيجان با ناكويى هيجانى در بيماران مبتلا به فشارخون بالا بود؛؛ ئرودئ
بحث و نتيجه تيرى

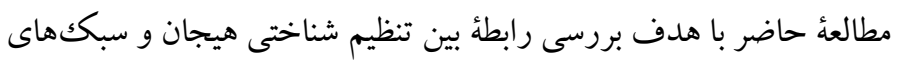

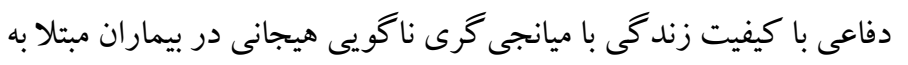

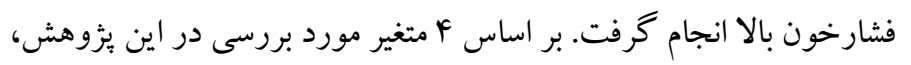
در ابتدا ارتباط بين تنظيم شناختى هيجان با كيفيت زندگ بحى در اين بيماران

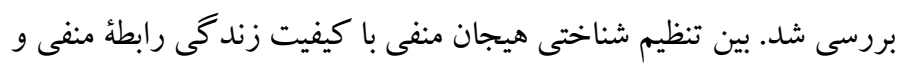

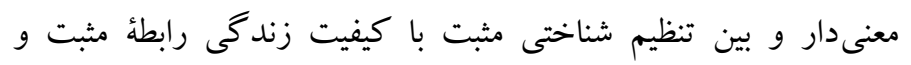

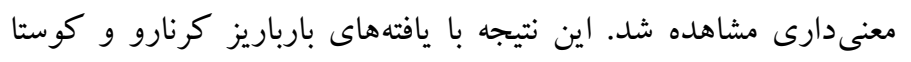
(Y.IV)

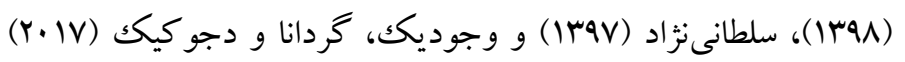
همخوانى داشت. اين نتايج را مى توان به شرح زير تبيين كرد. تنظيم هيجان و به خصوص راهبردهاى مثبت در كنترل هيجان، باعث كاهش احساسات منفى، افز ايش احساسات مثبت و رفتار ساز كارانه در افراد مىشود. در واقع، به كار گيرى راهبردهاى ساز گارانه باعث مى شود كه فرد

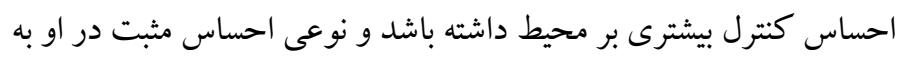

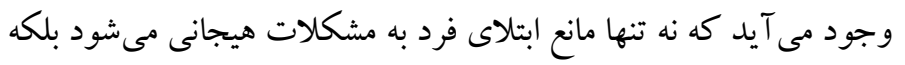
بر كيفيت زندكى او نيز اثر مثبت مى گذارد (بارباريز و همكاران، (Y.IV).

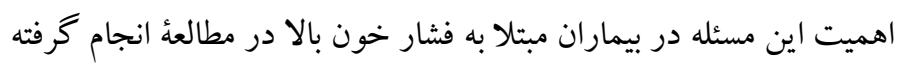

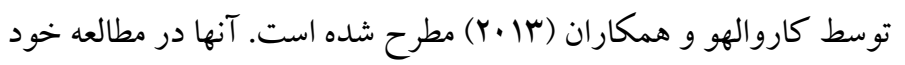
نشان دادند كه هر جه بيماران مبتلا به فشارخون بالا نسبت به هيجانات خود در موقعيتهاى تنشزا آكاه باشند و بتوانند به نحو مؤثرى آنها را كنترل

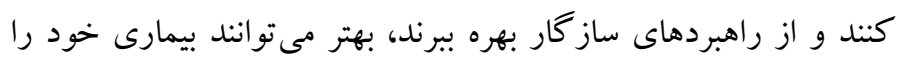

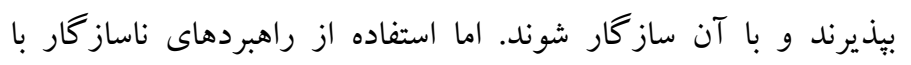
مشكلات هيجانى متعدد مانند اضطراب، افسردگى و برخاشخرى همراه

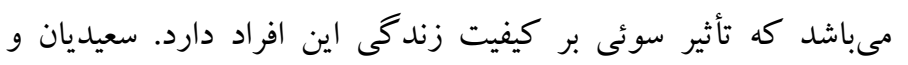

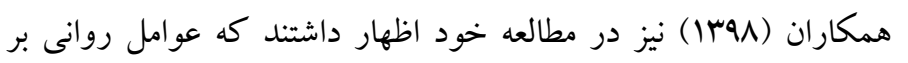
فشارخون و كيفيت زندكى تأثير دارند و كنترل آنها از طريق مداخلات روانشناختى به طور مستقيم بر كيفيت زندگى تأثير مى گذارد. آنها بيان

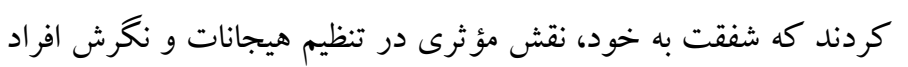

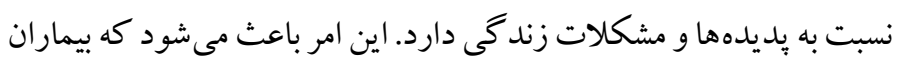

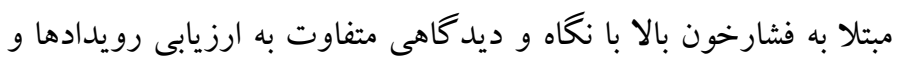

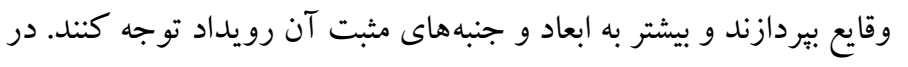


همكاران (Y.19) همخوانى داشت. اين نتايج را مىتوان به شرح زير تبين

افرادى كه دجار ناتوانى در يردازش شناختى هستند، به دليل اينكه

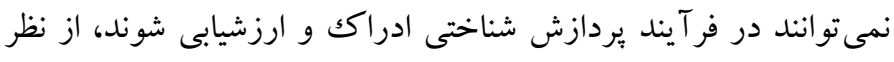

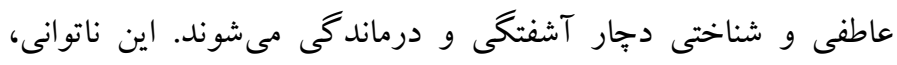
سازمان عو اطف و شناخت هاى فرد را مختل مى سازد و احتمال استفاده از ولى

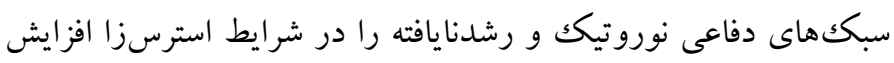

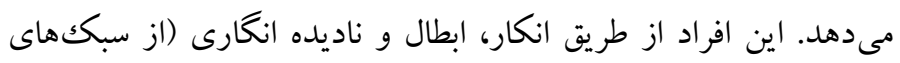
نوروتيكك و رشدنايافته) با موضوع استرس و شرايط استرسزا مواجه

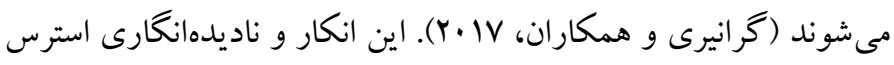
توسط اين افراد، رابطؤ مثبت بين ناكويى هيجانى و سبككهاى دهاى دفاعى

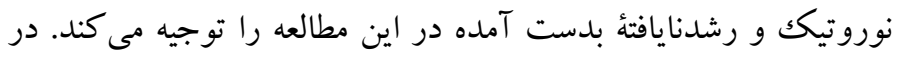

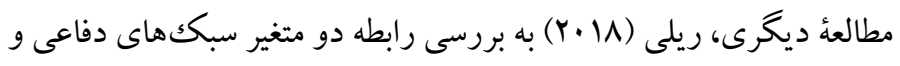

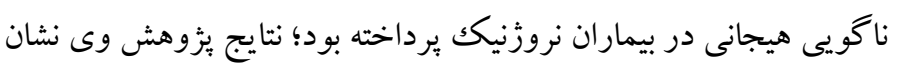

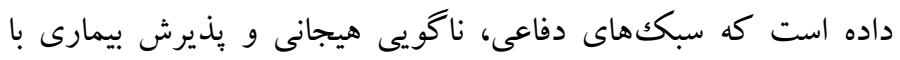

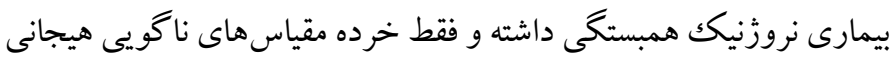

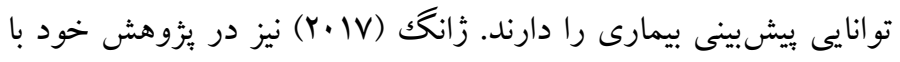

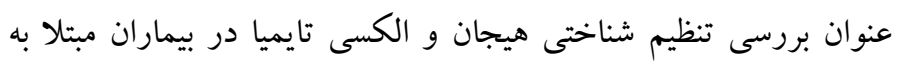

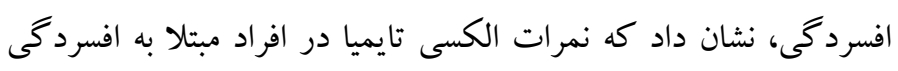

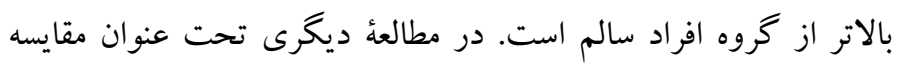

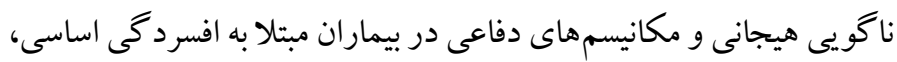
اضطراب فراگير، وسواس فكرى - عملى و جمعيت بهنجار كه توسط

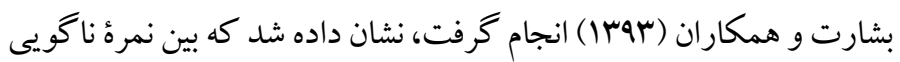

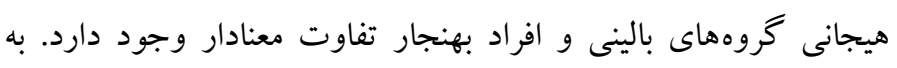

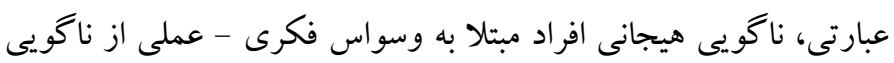

$$
\text { افر اد افسرده و مضطرب به صورت معنادار بيشتر بود. }
$$

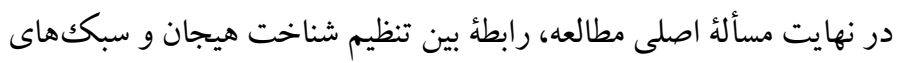

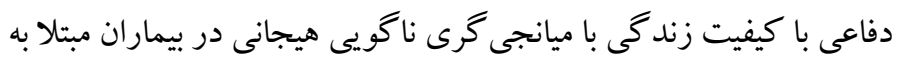
فشارخون بالا بررسى شد. نتايج بدست آمده ارتباط معنادارى را بين

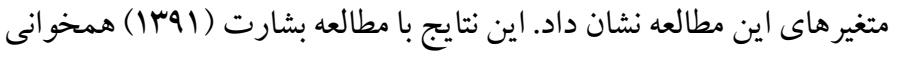

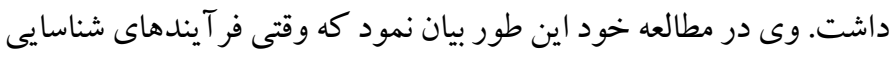
و توصيف احساسات به هر دليل مختل شود، درماندگى روانشناختى راههاى
نتايج نشان داد كه بين تنظيم شناختى هيجانى منفى با ناكويى هيجانى رابطه

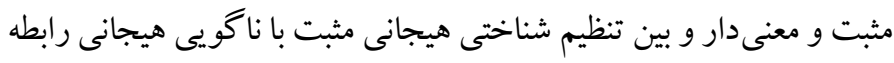

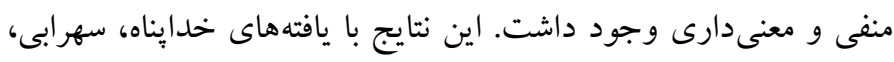

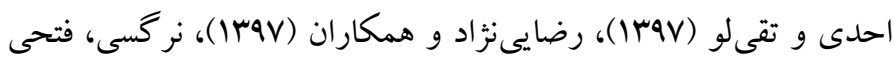

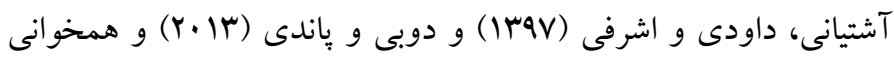
داشت. اين نتايج به صورت زير تبيين شد.

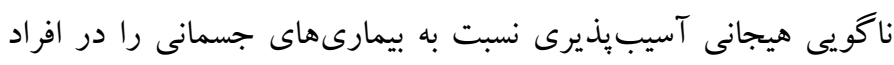

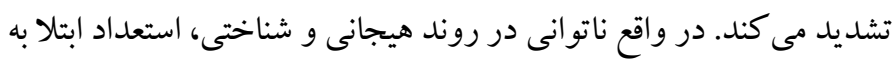

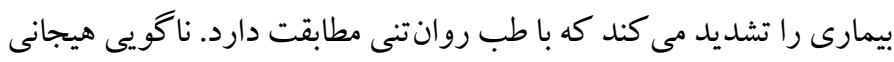
نقش مهمى در تنظيم هيجانات فرد ايفا مى كند و جنان جه شدات بـ يابد، آسيبذيذيرى فرد را در جهت ابتلا به اختلالهاى شخصيتى، اختلالهاى

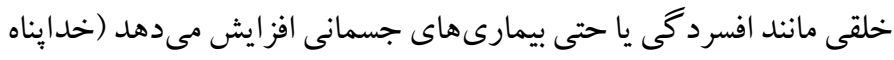

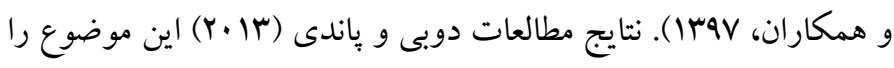
مطرح كرد كه افراد داراى ناكويى هيجانى نسبت به افراد عادى با احتمال بيشترى از راهبردهاى سركوبى استفاده مى كنند و كمتر از راهبردهاى ارزيابى مجدد بهره مى برند. راهبردهاى سر كوبى، رابطه بيشترى با مشكلات

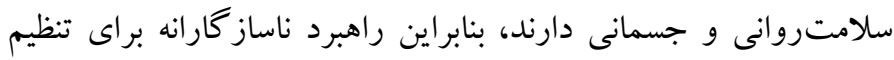

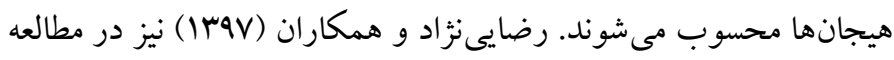

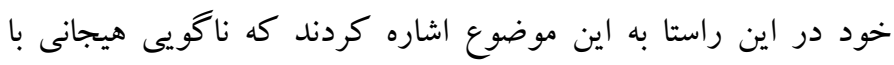

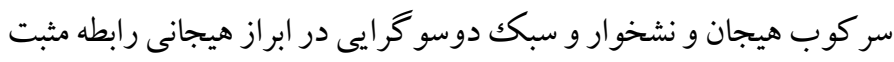

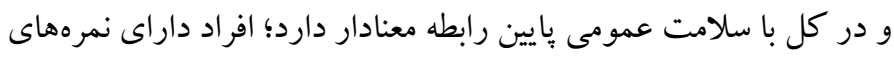
بالا در مقياس ناكويى هيجانى بيشتر از افراد واجد نمرههاى بايين در اين باين

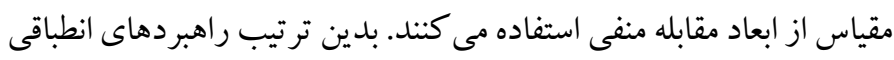
تنظيم شناختى هيجان، تنها زمانى به طور منفى با علائم آسيبشناختى رئى روانى

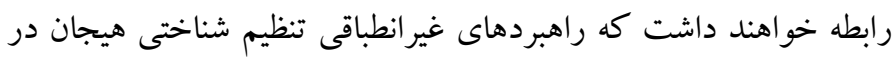
سطوح بالايى قرار داشته باشند. سبِ به بررسى رابطة بين سبك هاى دفاعى با ناكويى هيجانى در بيماران

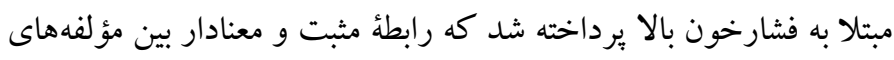

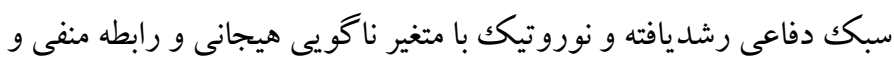

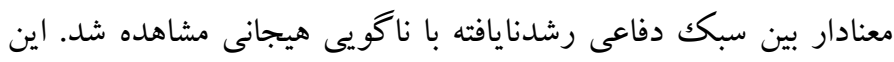

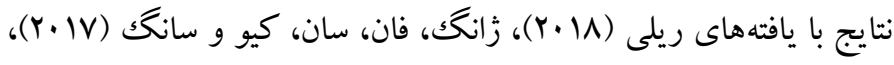

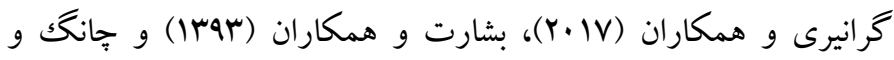


كه دجار افسرد گى بنهان هستند و اين وضعيت در آنها شناسايى نشده است، ارزيابى منفىترى از توانايىهاى خود ارائه مىدهند. يِيشنهاد مى شود

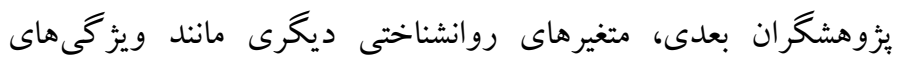

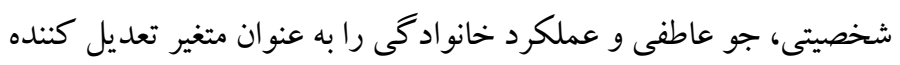

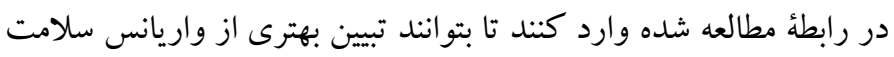

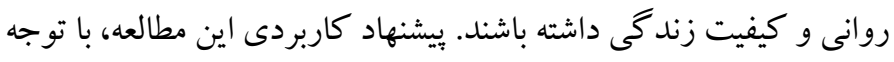

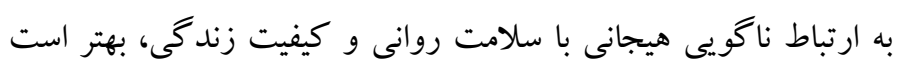

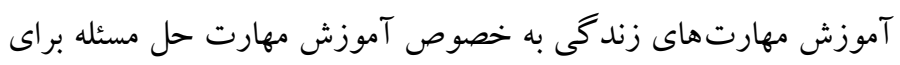

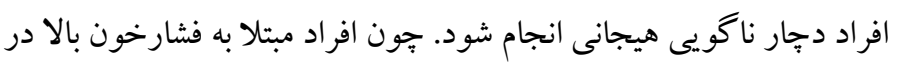

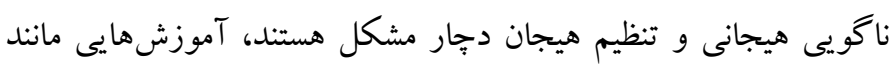

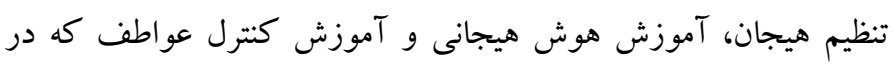
كاهش آشفتكى و مشكلات هيجانى مؤثر است، براى اين افراد بيشنهاد إنى مى كردد.

ملاحضات اخلاقى يبيروى از اصول اخلاق ئووهش: مقاله حاضر بخشى از رساله دكترى نويسنده اول

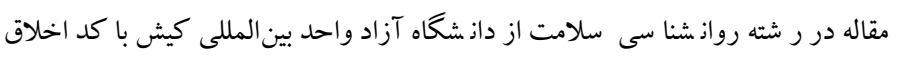

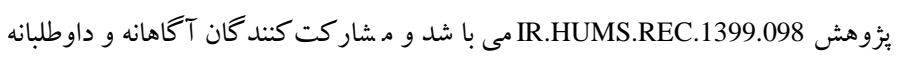

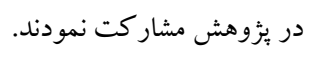

حامى مالى: يثوهش حاضر بر گرفته از رساله دكترى مىباشد كه توسط خود نوين نويسنده

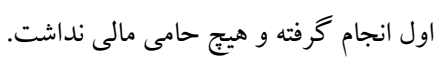

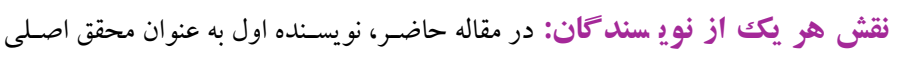

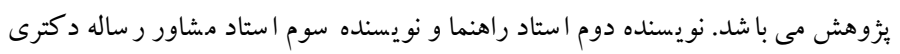

$$
\text { مىباشند. }
$$

تضاد منافع: هيج تضاد منافعى بين نويسند كان مقاله حاضر اعلام نشده است.

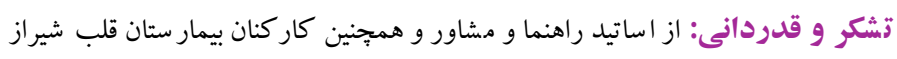
كه در انجام يزوهش حاضر يارى نمودند، تشكر و قدردانى مى گر ددد.
تحليل و تفكر منطقى را مىبندد و سبك شناختى فرد را به تفكر عينى، عمل كرا و واقعيتمدار محدود مى سازد. ترجيح فرد مبتلا به نارسايى رنى هيجانى به اين كه صرفاً شاهد وقايع باشد و به تحليل و تفسير آنها نبردازد ودارد

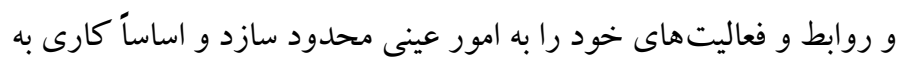

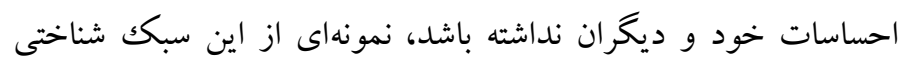

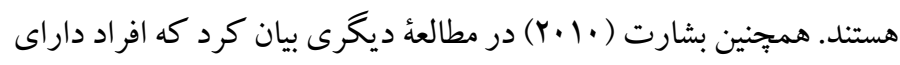
ناكويى هيجانى به فكر كردن در مورد مشكلات در شرايط استرسزا،

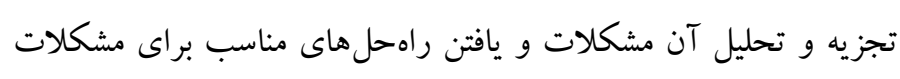

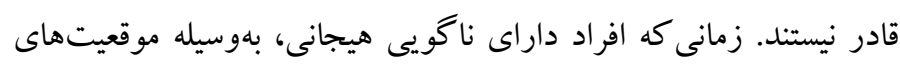

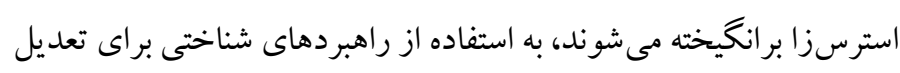

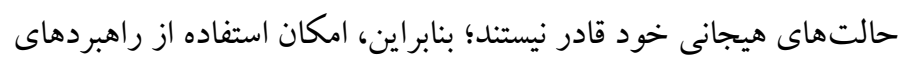
ناساز گارانه افزايش خواهد يانت

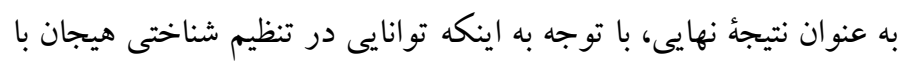

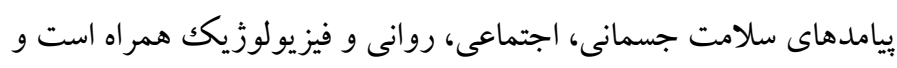

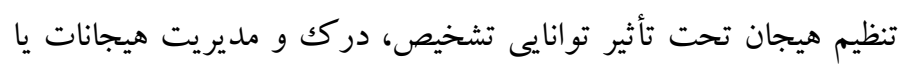

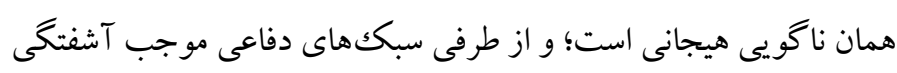
در سيستم هيجانى فرد مى شوند و ارتباط مستقيمى با ناكويى هيجانى دارند؛

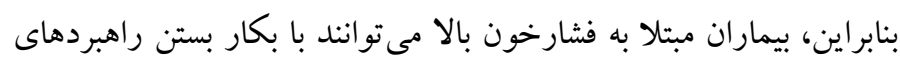

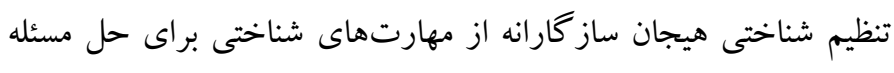
استفاده كرده و بر ناكويى هيجانى غلبه نمايند. همجنين در سائه انسجام

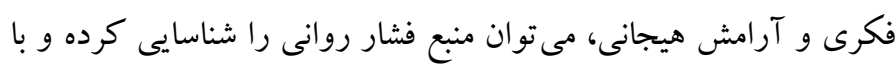

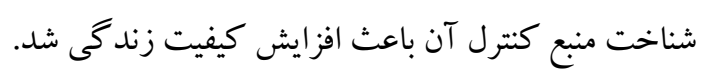

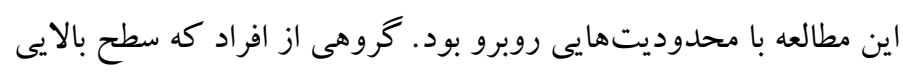

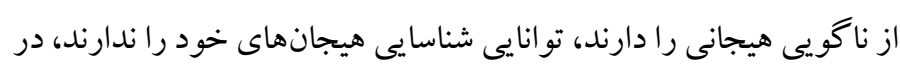

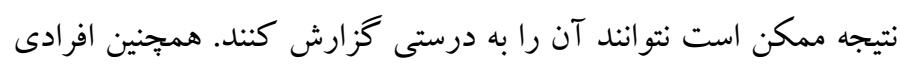




\section{References}

Ali Akbari Dehkordi, M, Salehi, Sh \& Rezaei, A. (2013). Comparison of irrational beliefs and defense styles between coronary heart patients and normal individuals. Journal of Health Psychology, 2 (6), 18-32. (Persian). [Link]

Andrews, G., Singh, M., \& Bond, M. (1993). The Defense Style Questionnaire. Journal of Nervous and Mental Disease, 181(4), 246-256. [Link]

Barańczuk, U. (2019). The five factor model of personality and alexithymia: A meta-analysis. Journal of Research in Personality, 78(1), 227-248. [Link]

Barberis, N., Cernaro, V., \& Costa, S. (2017). The relationship between coping, emotion regulation, and quality of life of patients on dialysis. The International Journal of Psychiatry in Medicine, 52(2), 1-10. [Link]

Besharat, M. A. (2012). The mediating role of defense mechanisms in the relationship between attachment and nagging styles. Journal of Applied Psychology, 6 (1), 22-7. (Persian). [Link]

Besharat, M. A. (2010). Relationship of alexithymia with coping styles and interpersonal problems. ProcediaSocial and Behavioral Sciences, 5(1), 614-618. [Link]

Besharat, M. A., \& Khajavi, Z. (2013). The relationship between attachment styles and alexithymia: Mediating role of defense mechanisms. Asian Journal of Psychiatry, 6(6), 571-576. [Link]

Besharat, M.A. (2013). Toronto Emotional Discomfort Scale: Questionnaire, Method of Execution and Scoring (Persian version) Journal of Transformational Psychology, 10 (37), 92-90. (Persian). [Link]

Blakey, S. M., Abramowitz, J. S., Reuman, L., Leonard, R. C., \& Riemann, B. C. (2017). Anxiety sensitivity as a predictor of outcome in the treatment of obsessive-compulsive disorder. Journal of Behavior Therapy and Experimental Psychiatry, 57(1), 113117. [Link]

Carey, R. M., \& Whelton, P. K. (2018). the 2017 American College of Cardiology/American Heart Association Hypertension guideline. Annals of internal medicine, 168(5), 351-358. [Link]

Carvalho, M. V., Siqueira, L. B., Sousa, A. L., \& Jardim, P. C. (2013). The influence of hypertension on quality of life. Arq Bras Cardiol, 100(1), 164-174. [Link]

Casagrande, M., Mingarelli, A., Guarino, A., Favieri, F., Boncompagni, I., Germanò, R., \& Forte, G. (2019).
Alexithymia: A facet of uncontrolled hypertension.International Journal of psychophysiology, 14(1), 180-189. [Link]

Chung, M. C., Di, X., \& Wan, K. H. (2016). Exploring the interrelationship between alexithymia, defense style, emotional suppression, homicide-related posttraumatic stress disorder and psychiatric comorbidity. Psychiatry Research, 30(2), 373-381. [Link]

Di Tella, M., Adenzato, M., Catmur, C., Miti, F., Castelli, L., \& Ardito, R. B. (2020). The role of alexithymia in social cognition: Evidence from a non-clinical population. Journal of affective disorders, 273(1), 482-492. [Link]

Dubey, A., \& Pandey, R. (2013). Mental health problems in alexithymia: Role of positive and negative emotional experiences. Journal of Projective Psychology \& Mental Health, 20(2), 128-136. [Link]

Esin, O., Gorobets, E., Khairullin, I., \& Esin, R. (2017). Alexithymia as a predictor of chronic tension headaches. BioNanoScience, 7(2), 272-27. [Link]

Frieden, T. R., \& Jaffe, M. G. (2018). Saving 100 million lives by improving global treatment of hypertension and reducing cardiovascular disease risk factors. The Journal of Clinical Hypertension, 20(2), 208211. [Link]

Garnefski, N., \& Kraaij, V. (2007). The cognitive emotion regulation questionnaire. European Journal of Psychological Assessment, 23(3), 141-149. [Link]

Gharibi, H, Rostami, Ch, Mohammadian Sharif, K \& Manqi, T. (2015). Predicting defense mechanisms based on quality of life and perceived socioemotional support in married women. Journal of Health and Care, 18 (1), 73-83. (Persian). [Link]

Granieri, A., La Marca, L., Mannino, G., Giunta, S., Guglielmucci, F., \& Schimmenti, A. (2017). The relationship between defense patterns and DSM-5 maladaptive personality domains. Frontiers in psychology, 8(2), 1926-1938. [Link]

Hyphantis, T. N., Taunay, T. C., Macedo, D. S., Soeirode-Souza, M. G., Bisol, L. W., Fountoulakis, K. N. \& Carvalho, A. F. (2013). Affective temperaments and ego defense mechanisms associated with somatic symptom severity in a large sample. Journal of affective disorders, 150(2), 481-489. [Link]

Ifeagwazi, C. M., Egberi, H. E., \& Chukwuorji, J. C. (2018). Emotional reactivity and blood pressure elevations: anxiety as a mediator. Psychology, health \& medicine, 23(5), 585-592. [Link] 
Jokar, F, Farhadi, M \& Delfan Biranvand, A. (2018). Predicting mental well-being based on cognitive emotion regulation strategies, defensive styles, honesty, and basic psychological needs. Journal of Psychological Studies, 14 (2), 73-57. (Persian). [Link]

Khoda panah, M, Sohrabi, F, Ahadi, H \& Taqiloo, S. (2018). Comparison of structural model of brainbehavioral system, impulsivity and emotional malaise with eating behavior. Iranian Journal of Health Education and Health Promotion, 6 (3), 265251. (Persian). [Link]

Martino, G., Caputo, A., Bellone, F.,Quattropani, M. C., \& Vicario, C. M. (2020). Going Beyond the Visible in Type 2 Diabetes Mellitus: Defense Mechanisms and Their Associations With Depression and Health-Related Quality of Life. frontiers in psychology, 11(1), 267. [Link]

McRae, K. (2016). Cognitive emotion regulation: A review of theory and scientific findings. Current Opinion in Behavioral Sciences, 10(1), 119-124. [Link]

Mehrabian, F., Farmanbar, R., Mahdavi Roshan, M., Omidi, S., \& Aghebati, R. (2017). Investigating the status of blood pressure and its related factors in individuals with hypertension visiting urban and rural health centers in Rasht City during 2014. $J$ Health, 8(3), 328-35. [Link]

Morris, S. S., Musser, E. D., Tenenbaum, R. B., Ward, A. R., Martinez, J., Raiker, J. S., \& Riopelle, C. (2020). Emotion regulation via the autonomic nervous system in children with attentiondeficit/hyperactivity disorder (ADHD): replication and extension. Journal of abnormal child psychology, 48(3), 361-373. [Link]

Nargesi, F, Fathi Ashtiani, A, Davoodi, I \& Ashrafi, E. (2018). The relationship between mood distress, anxiety sensitivity and distress tolerance with obsessive-compulsive symptoms mediated by dysfunctional emotion regulation strategies in students. Journal of Disability Studies, 8 (15), 9-9. (Persian). [Link]

Nejat, S, Montazeri, A, Holakouee Naeini, K, Mohammad, K \& Majdzadeh, R. (2006). Standardization of the World Health Organization Quality of Life Questionnaire: Translation and Psychometrics of the Iranian Species. Journal of Health and Institute of Health Research, 4 (4), 14-1. (Persian). [Link]

Nejat, S., Montazeri, A., Holakouie Naieni, K., Mohammad, K. A. Z. E. M., \& Majdzadeh, S. R. (2006). The World Health Organization quality of
Life (WHOQOL-BREF) questionnaire: Translation and validation study of the Iranian version. Journal of school of public health and institute of public health research, 4(4), 1-12. [Link]

Nemat Tavousi, M. (2017). The mediating role of academic motivation in the relationship between self-esteem and quality of life. Journal of Psychological Sciences, 16 (61), 85-104. (Persian). [Link]

Pazuki, L, Kuchak Entezar, R \& Ghanbari Panah, A. (2015). Psychometric Properties of Cognitive Emotion Regulation Questionnaire. Psychometrics, 4 (14), 11-. (Persian). [Link]

Porcelli, P., De Carne, M., \& Leandro, G. (2017). The role of alexithymia and gastrointestinal-specific anxiety as predictors of treatment outcome in irritable bowel syndrome. Comprehensive Psychiatry, 73(1), 127135. [Link]

Rafiei, N, Sharifian Thani, M, Rafiei, H, Behnampour, N \& Foroozeh, K. (2014). Assessing the reliability and validity of the Persian version of the Quality of Life Index questionnaire. Journal of Mazandaran University of Medical Sciences, 24 (116), 83-75. (Persian). [Link]

Reilly, L. (2018). LSRP: Defense Styles, Alexithymia, Illness Perceptions, and HRQOL in IBD. Systematic Lit: Neurodegenerative Diseases and Third Wave Therapies (Doctoral dissertation, Queen's University Belfast. Faculty of Engineering and Physical Sciences, December). [Link]

Rezaeinejad, N, Moradi, O, Hassani, R \& Sajjadi, P. (2018). Predicting mood dysphoria based on main family health, self-differentiation and cognitive emotion regulation in female students. Zanko Journal of Medical Sciences, 19 (61), 42-32. (Persian). [Link]

Saeidian, K, Sohrabi, A \& Zemstani, M. (2019). The effectiveness of compassion-focused treatment on blood pressure and quality of life in women with hypertension. Journal of Ilam University of Medical Sciences, 27 (1), 161-169. (Persian). [Link]

Santorelli, G. D., \& Ready, R. E. (2015). Alexithymia and executive function in younger and older adults. The Clinical Neuropsychologist, 29(7), 938-955. [Link]

Soltani Nejad, M. (2018). Investigating the relationship between self-differentiation and cognitive regulation of emotion with quality of life in women with breast cancer. Iranian Breast Diseases Quarterly, 11 (1), 66-58. (Persian). [Link]

Talepasand, S., \& Mahfar, F. (2018). Relationship between defense mechanisms and the quality of life 
in women with breast cancer. International Journal of Cancer Management, 11(1). [Link]

Tavakoli, Z, Tajeri, B, Radfer, S, Jamhari, F \& Khosravi, A. (2020). The effectiveness of acceptance-based behavioral therapy on latent anxiety, overt anxiety and hypertension in cardiovascular patients referred to Baqiyatallah Hospital ... Journal of Psychological Sciences. 19 (96), 1655-1666. (Persian). [Link]

Taylor, G. J., Bagby, R. M., \& Luminet, O. (2000). Assessment of alexithymia: Self-report and observer-rated measures. The handbook of emotional intelligence, 301-319. [Link]

Vojvodic, A., Gordana, D., \& Djukic-Dejanovic, S. (2017). Defense mechanisms and quality of life in military personnel with burnout syndrome. Military-medical and Pharmaceutical Review, 76(1), 114-120. [Link]

World Health Organization. (1996). WHOQOL-BREF: introduction, administration, scoring and generic version of the assessment: field trial version, December 1996 (No. WHOQOL-BREF). World Health Organization. [Link]

Yousefi, F. (2006). The relationship between emotional intelligence and communication skills in students. Transformational Psychology, 3(9), 13-5. (Persian). [Link]

Zhang, H., Fan, Q., Sun, Y., Qiu, J., \& Song, L. (2017). A study of the characteristics of alexithymia and emotion regulation in patients with depression. Shanghai archives of psychiatry, 29(2), 95-103. [Link] 